\title{
Economic Fundamentals, Capital Expenditures and
}

\author{
Asset Dispositions
}

\author{
Brent W. Ambrose* * Eva Steiner ${ }^{\dagger}$
}

September 20, 2017

\begin{abstract}
Research on the disposition effect in real assets to date ignores the active management component of these investments. Active management notably includes decisions about follow-up investment in the form of capital expenditures, as well as dispositions. Using a real option framework, we develop testable hypotheses and provide empirical evidence for the relationships between economic fundamentals, capital expenditures, property values, and the subsequent likelihood of sale. Our results shed new light on the evidence for the disposition effect.
\end{abstract}

* Smeal College of Business, Pennsylvania State University, 381 Business Building, University Park, PA 16802 (e-mail: bwa10@psu.edu).

${ }^{\dagger}$ Corresponding author: School of Hotel Administration, Cornell SC Johnson College of Business, 465B Statler Hall, Ithaca, NY 14853 (email: ems457@cornell.edu). We are thankful for comments from Robert Connolly, Davi Geltner, David Ling, Crocker Liu, Tim Riddiough, Jacob Sagi, and Susan Wachter, as well as seminar participants at the AREUEA National Meeting 2017. We gratefully acknowledge financial support from the Real Estate Research Institute (RERI). We are also grateful to the National Council of Real Estate Investment Fiduciaries for providing the data used in this study. 


\section{Introduction}

The disposition effect denotes a behavioral bias leading investors to hold poorly performing investments to avoid realizing losses. ${ }^{1}$ It was first documented in financial assets such as stocks and mutual funds (Coval and Shumway, 2005; Dhar and Zhu, 2006; Frazzini, 2006; Ivković, Poterba, and Weisbenner, 2005; Odean, 1998). Recent evidence suggests that investors in real assets such as real estate also may be subject to the disposition effect (Bokhari and Geltner, 2011; Crane and Hartzell, 2010; Genesove and Mayer, 2001). However, unlike financial securities, one of the strongest distinguishing features real assets like real estate is the requirement of active management of daily operational activities that include general maintenance as well as decisions regarding subsequent investment in the property (i.e., capital expenditures.) Furthermore, it is unclear how these active management decisions influence disposition choices. As a result, an alternative rational explanation may exist to explain the observed disposition effect whereby investors pursue a value-add strategy and keep a property until they have made sufficient improvements to realize a profit on the sale. Such a property may well perform poorly in the interim and thus could result in outcomes that are observationally similar to the disposition effect. We focus on this alternative explanation for observed disposition patterns.

We model investment in capital expenditures (CAPEX) as a real option to restore an asset that has suffered physical depreciation and economic obsolescence to its new, undepreciated

\footnotetext{
${ }^{1}$ Shefrin and Statman (1985) introduce the concept of loss aversion, which draws upon prospect theory (Kahneman and Tversky, 1979), mental accounting (Shefrin and Thaler, 2004; Thaler, 2004, 2008), aversion to regret (Kahneman and Tversky, 1982; Thaler, 1980), and the ability to exercise self-control (Shefrin and Thaler, 2004). See Ben-David and Hirshleifer (2012) for a concise summary of the literature. DellaVigna (2009) also provides a general survey of the evidence on reference dependence.
} 
state. We then consider the investor's real option to sell the asset by introducing the concept of highest and best use versus second best use into the model. By combining the optimal time to invest in CAPEX with the highest and best use assumption, we develop a set of testable hypotheses about the occurrence of CAPEX as a function of the economic environment, the implications for asset value, and the likelihood of sale following CAPEX investments. As a result, we are able to offer novel insights into the disposition effect in real assets.

We test our empirical predictions in a sample of commercial property investments obtained from the National Council of Real Estate Investment Fiduciaries (NCREIF) over the period 2001 to 2014. NCREIF is the leading provider of proprietary investment performance and data on financial as well as physical characteristics for US commercial real estate assets. The data set comprises observations on large, institutional-grade assets owned by pension funds and insurance companies. Unlike any other data source on any other type of real estate that we are aware of, NCREIF offers detail on asset-level follow-up investments in the form of CAPEX. At the same time, the data set is rich in asset details, allowing us to control for a wide array of observable property and financial characteristics that aid identification by reducing omitted variable bias. The time-series dimension of the data set, which spans more than one full real estate market cycle, allows us to incorporate lag structures into our estimation to address simultaneity bias. Further, the data set includes unique information about asset-level appreciation returns through time, allowing us to contrast the evidence for our proposed hypotheses directly with the evidence for the disposition effect, which is based on the relationship between past appreciation returns and disposition choices.

We first document the cross-sectional and cyclical patterns of different types of CAPEX. 
Consistent with our hypotheses, we find that investors increase expansion and improvement CAPEX during periods with higher expected market-level income growth, and reduce these CAPEX in periods with higher volatility of those growth expectations. Conversely, we find that investments in tenant incentives and lease commissins (TIs) decline during periods of higher income growth expectations. Our findings suggest that, as leasing market conditions improve, owners are less compelled to offer tenant incentives or lease commissions.

Next, we analyze the effect of CAPEX on asset market value. We find that CAPEX are partially capitalized into asset values. Our results suggest that approximately 30 percent of expansion and improvement CAPEX and 25 percent of TIs are capitalized into subsequent asset market values, respectively. Investors may find these estimates useful when forming expectations about the return to CAPEX projects.

In the final step of our analysis, we reexamine the evidence for the disposition effect. When we ignore active management in the form of CAPEX, we find a positive and significant relationship between past appreciation returns and the subsequent likelihood of sale, consistent with the behavioral bias to sell winners and hold losers in an attempt to avoid realizing losses. However, after accounting for active management in the form of CAPEX, and the underlying economic drivers as suggested by real option theory, the evidence for the disposition effect vanishes. Thus, in the context of the debate about the disposition effect in real estate our findings suggest that the empirical evidence for this effect may in fact depend on accounting for the active management components of commercial real estate investment.

Our work broadly relates to the literature in behavioral finance that addresses seemingly 
irrational choices by investors and managers. Some assume that managers are subject to behavioral biases (Ben-David and Graham, 2013; Gabaix, 2014). An alternative view is that managers respond rationally to behavioral biases among investors. ${ }^{2}$ Our findings suggest that there may be a rational explanation that does not involve behavioral biases on the part of investors or managers.

We are not the first to offer a rational alternative explanation for the disposition effect, but existing studies focus on stocks. For example, Ben-David and Hirshleifer (2012) argue that the disposition effect may be explained by trading based on belief revisions. Dorn and Strobl (2015) show that the effect may result as a rational response to differential access to information. Seru, Shumway, and Stoffman (2010) find that it may be alleviated through trading experience. Dai, Liu, and Xu (2015) argue that active portfolio management can produce the disposition effect. We show that there is also an alternative rational explanation for the disposition effect observed in real estate, related to the active management requirement that is typical for the asset class.

Others have studied seemingly irrational choices in real estate. With the exception of Genesove and Mayer's (2001) evidence on the disposition effect, the work in this area often focuses on mortgage choices (see, e.g. Guiso, Sapienza, and Zingales (2013)). Seemingly irrational financing choices in real estate are commonly linked to a lack of financial sophistication (Agarwal, Ben-David, and Yao, 2017; Agarwal and Mazumder, 2013; Agarwal, Rosen, and Yao, 2016). In contrast, we focus on a set of large-scale institutional real estate investors

\footnotetext{
${ }^{2}$ Studies in this vein analyze the effects of security mis-pricing on corporate policies (Baker, Greenwood, and Wurgler, 2003; Baker, Stein, and Wurgler, 2003; Baker and Wurgler, 2002, 2004; Graham and Harvey, 2001; Polk and Sapienza, 2009).
} 
that are arguably more financially sophisticated. Nonetheless, we are able to replicate the disposition effect in our sample. However, our results suggest that the evidence for the disposition effect depends not on the level of sophistication among real estate investors but on whether one accounts for the active management component of real estate.

The remainder of our study is organized as follows: Section 2 outlines our theoretical model. Section 3 describes the resulting testable hypotheses, empirical method and data. Sections 4 and 5 discuss data and empirical results. Section 6 concludes.

\section{Theory}

\subsection{Model setup}

We adopt the real option analysis from Dixit and Pindyck (1994), Pindyck (1988), and Bertola (1998) for incremental investment problems to the case of commercial real estate to highlight the optionality associated with capital expenditure investment decisions. Abstracting from discussion of fixed and variable costs, we assume that an asset generates a simple profit flow (net operating income or NOI) of $\pi=H M(K)$, where $M(K)$ is a concave function of capital $(K)$ invested in the asset, and $H$ is a random shift variable reflecting uncertainty over future NOI. We assume that $H$ can be described by the geometric Brownian motion

$d H_{t}=\alpha_{H} H_{t} d t+\sigma_{H} H_{t} d z_{H}$

where $\alpha_{H}$ and $\sigma_{H}$ are the expected growth rate and volatility associated with NOI, respectively, and $E\left[d z_{H}^{2}\right]=d t$. For analytical convenience, we assume that $M(K)$ takes a specialized Cobb-Douglas form $M(K)=K^{\theta}, 0<\theta<1$. Further, $\kappa$ represents the unit cost of capital. 


\subsection{Depreciation and capital expenditures}

If we assume that physical depreciation and economic obsolescence occurs exponentially through time following a Poisson process, then over a small time increment of $d t$, the invested capital in the asset will depreciate with probability $\lambda K d t$. Furthermore, assuming no investments in capital expenditures, then the asset will depreciate at the rate $d K=-\lambda K d t$ and the NOI flow at time $t$ is $H_{t} M\left(K e^{-\lambda t}\right)$.

Thus, the expected value of the asset at the date of purchase is

$V(K, H)=\hat{E} \int_{0}^{\infty} H_{t} M\left(K e^{-\lambda t}\right) e^{-\rho t} d t$

where $\rho$ is the discount rate. Using Ito's lemma, we can show that (2) is the solution to the following differential equation

$\frac{1}{2} \sigma^{2} H^{2} \frac{\partial^{2} V}{\partial H^{2}}+\alpha H \frac{\partial^{2} V}{\partial H}-\lambda K \frac{\partial V}{\partial K}-\rho V+H M(K)=0$.

Next, we note that if the owner makes capital expenditures of $d K_{g}$, then the change in capital invested in the asset is given as

$d K=d K_{g}-\lambda K d t$

and we denote the option to make these investments as $F(K, H)$. Using the usual assumptions associated with the contingent claims approach to real option models regarding the creation 
of a replicating portfolio with an asset spanning $\mathrm{H}$, we get

$\frac{1}{2} \sigma^{2} H^{2} \frac{\partial^{2} F}{\partial H^{2}}+(r-\delta) H \frac{\partial F}{\partial H}-\lambda K \frac{\partial F}{\partial K}-r F=0$

where $r$ is the risk-free rate, $\delta=\mu-\alpha_{H}$, and the risk-adjusted discount rate $\mu$ is used in place of $\rho$. Differentiating (5) with respect to capital $K$ results in the following equation for the value of the marginal capital expenditure investment option $(f(K, H))$ :

$\frac{1}{2} \sigma^{2} H^{2} \frac{\partial^{2} f(K, H)}{\partial H^{2}}+(r-\delta) H \frac{\partial f(K, H)}{\partial H}-\lambda K \frac{\partial f(K, H)}{\partial K}-(r+\lambda) f(K, H)=0$

Since $M(K)=K^{\theta}$ by assumption, we can assume that the capital expenditure option depends on the composite variable $h=H K^{\theta-1}$. Thus, substituting $\frac{\partial f(K, H)}{\partial H}=K^{\theta-1} g^{\prime}(h)$ where $f(K, H)=g(h)$ yields

$\frac{1}{2} \sigma^{2} h^{2} \frac{\partial^{2} g(h)}{\partial h^{2}}+[r-(\delta+\lambda(\theta-1))] h \frac{\partial g(h)}{\partial h}-(r+\lambda) g(h)=0$.

Equation (7) has the solution

$g(h)=B h^{\beta_{1}}$

where $\beta_{1}$ is the positive root of the quadratic that corresponds to equation (7). ${ }^{3}$ Following the

$$
{ }^{3} \beta_{1}=\frac{1}{2}-\left(r-(\delta+\lambda(\theta-1)) / \sigma^{2}+\sqrt{\left[(r-(\delta+\lambda(\theta-1))) / \sigma^{2}-\frac{1}{2}\right]^{2}+2 r / \sigma^{2}}\right.
$$


exposition in Dixit and Pindyck (1994), the optimal income $\left(H^{*}\right)$ that triggers investments in capital expenditures is

$H^{*}=\frac{\beta_{1}}{\beta_{1}-1} \frac{(\delta+\lambda \theta) \kappa}{\theta K^{\theta-1}}$

From equation (9), we can see that an increase in the growth rate associated with income $(\alpha)$ reduces the critical value necessary to trigger capital expenditures and thus decreases the delay between capital expenditure investments. ${ }^{4}$ Next, an increase in the volatility surrounding income $(\sigma)$ increases the trigger value and thus results in a longer time between capital expenditure investments. These relationships are illustrated numerically in Figure 1.

[Figure 1 about here.]

\subsection{The disposition decision}

The asset's current owner, as the marginal investor, deploys the building at its highest and best use, which is assumed to follow the income process described in equation (1). The concept of highest and best use (HBU) implies that owners maximize value, or else there is an incentive to trade. ${ }^{5}$ To capture this incentive, we assume that the building could be redeployed by a new owner at a second best use (SBU), realizing an income flow that corresponds to a random shift variable $(S)$ reflecting uncertainty over future income. As

\footnotetext{
${ }^{4}$ This implicitly assumes that rents are reviewed or leases renewed so that rents can be reset to the prevailing market level.

${ }^{5}$ Investors may also refinance rather than sell. We recognize this possibility but do not model it explicitly in this study.
} 
above, we assume that this shift variable is described by a geometric Brownian motion:

$d S_{t}=\alpha_{S} S_{t} d t+\sigma_{S} S_{t} d z_{S}$

where $\alpha_{S}$ and $\sigma_{S}$ are the expected growth rate and volatility associated with the SBU income, respectively, and $E\left[d z_{S}^{2}\right]=d t$. Thus, as with the case of the highest and best use and recognizing that an asset deployed at its SBU also depreciates at the rate $-\lambda K d t$, the value of the asset when utilized at its the second best income flow is given as

$V(K, S)=E \int_{0}^{\infty} S_{t} M\left(K e^{-\lambda t}\right) e^{-\rho t} d t$

with $V(K, H)>V(K, S)$. We now focus on the evolution of $H$ and $S$ through time that creates opportunities to trade. We note that the current owner's opportunity to sell the asset is equivalent to a perpetual put option. In this context, we denote the value of the option to sell as $W(K, H, S)$ since it is a function of two stochastic variables. The payoff at any time $t$ to selling the asset is $V(K, S, t)-V(K, H, t)$. Thus, the owner maximizes the present value of the payoff:

$W(K, H, S)=\max \hat{E}[(V(K, S, T)-V(K, H, T)), 0] e^{-\mu T}$

where $T$ is the unknown future date that the asset is sold, and $\mu$ is the discount rate. Using Ito's Lemma and denoting the correlation between $H$ and $S$ as $\rho_{H S}$ with $E\left[d z_{H} d z_{S}\right]=\rho_{H S} d t$, 
the value of this disposition option is the solution to the following partial differential equation:

$d W=\frac{1}{2}\left[\sigma_{H}^{2} H^{2} \frac{\partial^{2} W}{\partial H^{2}}+\sigma_{S}^{2} S^{2} \frac{\partial^{2} W}{\partial S^{2}}+2 \rho_{H S} \sigma_{H} \sigma_{S} H S \frac{\partial^{2} W}{\partial H \partial S}\right]+\frac{\partial W}{\partial H} d H+\frac{\partial W}{\partial S} d S$

Equation (13) is a complex partial differential equation that needs to be solved numerically. The complication arises by recognizing the path dependency inherent in the capital expenditure option. That is, the HBU value of the asset at any point $t$ that determines whether it is optimal to sell to the second best user is conditional on knowing whether the owner invested in capital expenditures during the period prior to $t$.

We note that: (i) A higher growth rate in current HBU income $\left(\alpha_{H}\right)$, all else constant, decreases the threshold for capital expenditures, increasing asset value. This results in reducing the payoff and probability of sale; (ii) A higher growth rate in SBU income $(S)$, all else constant, increases the probability of sale. Thus, the probability of sale is a function of the relative difference in the income growth rates. In other words, the probability of sale is an increasing function of the ratio of the SBU income growth rate to the HBU income growth rate $\left(\frac{\alpha_{S}}{\alpha_{H}}\right)$. Similarly, the probability of selling increases as the ratio of SBU income volatility $\left(\sigma_{S}\right)$ to HBU income volatility $\left(\sigma_{H}\right)$ increases. An increase in $\sigma_{H}$ lowers the probability of capital expenditures and thus increases the probability of sale. ${ }^{6}$

The option to invest in capital expenditures impacts the decision to sell in two ways. First, past investments in capital expenditures increase the HBU valuation and thus reduce the

\footnotetext{
${ }^{6}$ Although not explicitly modeled, we recognize that differences in expectations regarding economic and physical depreciation between the HBU and SBU may also alter the probability of sale. For instance, if assets deployed at HBU require higher levels of maintenance or experience greater utilization than SBU assets, then the probability of sale will increase.
} 
payoff from selling to the SBU investor, reducing the probability of sale. Second, the option to make future capital expenditures to offset the effects of depreciation increases the asset value to the $\mathrm{HBU}$ owner, again lowering the potential payoff from disposition and reducing the probability of sale. However, increases in HBU depreciation relative to SBU depreciation increase the threshold for capital expenditures and thus lower the asset value. Figure 2 illustrates these relationships and suggests that on balance, the probability of sale declines in capital expenditures.

[Figure 2 about here.]

\section{Empirical approach}

\subsection{Testable hypotheses}

The discussion of the simple real option model allows us to formulate a set of empirically testable hypotheses. First, we note that an increase in expected income reduces the threshold value of income that triggers capital expenditures, thus decreasing the delay between capital expenditures. In other words, higher expected income growth increases the payoff and likelihood of capital expenditures.

Hypothesis 1: An increase in expected income growth increases subsequent capital expenditures.

Based on the real option framework, keeping everything else constant, uncertainty increases the value of keeping the option alive and not exercising in the current period. Therefore, an increase in the volatility of expected income growth raises the threshold value of income 
necessary to carry out capital expenditures and thus produces a longer time delay between capital expenditure investments, reducing their likelihood.

Hypothesis 2: Higher expected income growth volatility reduces subsequent capital expenditures.

Next, the model implies that CAPEX will increase the value of the asset. The rationale is as follows. As per hypothesis 1, higher income growth is associated with an increased likelihood of CAPEX, and results in higher asset values. At the same time, asset values increase with CAPEX because CAPEX restore the asset to an undepreciated state and enable the owner to capture the full market rent (assuming that leases are up for renewal), reinforcing the positive effect on values.

Hypothesis 3: An increase in CAPEX increases asset value.

Further, the model predicts a lower likelihood of sale following higher CAPEX. Again, this is implicit in the model. Higher CAPEX implies a higher HBU asset value and thus the probability that the SBU value will be greater than the HBU value is reduced, all else being equal. Therefore, the probability of a sale declines following higher CAPEX.

Hypothesis 4: Higher capital expenditures reduce the subsequent likelihood of sale.

\subsection{Empirical tests}

To formally test hypotheses 1 and 2, we estimate the following OLS model of the annual capital expenditures per square foot for asset $i$ at time $t\left(C A P E X_{i, t}\right)$ as a function of income 
growth expectations and their volatility:

$C A P E X_{i, t}=\gamma_{0}+\gamma_{1} G E_{i, t-1}+\gamma_{2} V O L_{i, t-1}+\gamma_{3} \mathbf{X}_{i, t-1}+u_{i t}$

where $\gamma$ denotes the coefficients to be estimated, $G E_{i, t-1}$ is the expected rate of asset income growth at time $t-1, V O L_{i, t-1}$ is the volatility of income growth expectations during year $t-1, \mathbf{X}_{t-1}$ is a matrix of control variables measured at time $t-1$, and $u_{i t}$ is the residual.

For CAPEX, we distinguish between expansion and improvement projects as well as tenant incentives and lease commissions. Capital expenditures associated with tenant incentives and lease commissions are often part of the negotiation over leasing and thus reflect market leasing conditions, not an effort to restore the asset to an undepreciated state. Our hypothesis development on the other hand is more closely associated with value-enhancing improvement and expansion projects that alter the physical structure of the asset to restore its quality. Therefore, we primarily focus on capital improvements and expansion capital expenditures, but use the data on tenant incentives and lease commissions as contrasting evidence.

The control variables include CPI inflation to account for changes in the price level, which may inflate CAPEX values. We control for building-level occupancy, as CAPEX are unlikely unless space is vacant. We control for the age of the asset at acquisition because age influences CAPEX (Bokhari and Geltner, 2016). We also control for asset size (measured as the natural logarithm of square footage), past performance in terms of annual income and appreciation returns, as well as the prevailing cap rate and transaction volume, by property type and MSA, as proxies for liquidity and risk in the asset's market sector. The right hand side variables are 
lagged by one year in order to address endogeneity. We include fixed effects for property type, investor type (fund type) and geographic region (division). Standard errors are clustered by asset. Consistent with Hypotheses 1 and 2, we expect a positive value for $\gamma_{1}$ and a negative value for $\gamma_{2}$.

We test hypothesis 3 by estimating the following OLS model of the natural logarithm of the market value for asset $i$ at the end of year $t$ as a function of CAPEX (on expansion and improvement as well as tenant incentives and lease commissions) over the previous year $t-1$ :

$\ln \left(M V_{i, t}\right)=\gamma_{0}+\gamma_{1} \ln \left(C A P E X_{i, t-1}\right)+\gamma_{2} \mathbf{X}_{i, t-1}+u_{i t}$

where notation, control variables, and fixed effects are as in Equation (14). The log-log specification allows us to interpret the coefficients as the marginal effect on market value in percent for a one-percent increase in CAPEX. The lagged specification allows us to address the issue that actual market value effects of CAPEX may enter valuations with a lag. ${ }^{7}$ Standard errors are clustered by asset. Consistent with hypothesis 3, we expect a positive value on coefficient $\gamma_{1}$.

A relevant practical question for real estate owners is whether any increase in market value is directly proportional to the cost of CAPEX. If that is the case, then $\gamma_{1}=1$. If $\gamma_{1}<1$, then CAPEX may increase market value but may not improve return on investment. Investors are then able to adjust their expected return on CAPEX investments accordingly.

\footnotetext{
${ }^{7}$ Our approach is unlikely to fully mitigate the issue, so our estimates are conservative.
} 
To test hypothesis 4 , we estimate a Logit model where the dependent variable takes the value of 1 if the asset was sold by the end of year $t$ :

Sale $_{i, t}=\gamma_{0}+\gamma_{1} C A P E X_{i, t-1}+\gamma_{2} \mathbf{X}_{i, t-1}+u_{i t}$.

The notation, control variables, and fixed effects are as above. CAPEX refers to expansion and improvement CAPEX as well as tenant incentives and lease commissions over the year $t-1$. Standard errors are clustered by asset. Consistent with hypothesis 4 , we expect a negative sign on the coefficient $\gamma_{1}$.

In this step of the analysis, we estimate alternative versions of this model that allow us to examine the empirical evidence for the disposition effect increasingly documented in the real estate literature (Bokhari and Geltner, 2011; Crane and Hartzell, 2010; Genesove and Mayer, 2001). We test for the disposition effect by examining the coefficient estimate on the lagged asset-level appreciation return, which is included in our set of control variables. According to the literature on the disposition effect, the coefficient estimate should be positive and significant, as investors sell strongly performing properties and hold on to poorly performing investments in an attempt to avoid realizing a loss.

\subsection{Identification}

In testing Hypotheses 1 and 2, the identifying assumption is that variation in expected income growth and income growth volatility is exogenous to the property investment in question. We believe that this assumption is satisfied because these variables refer to market level expectations of income growth and volatility where the market is defined by property sector, 
MSA (location) and year, not the asset itself. Given the large number of assets in each market (property sector/ geographic location / year cell), it is unlikely that a given asset would overly influence the growth rate and volatility in the market.

In testing Hypothesis 3, a potential threat to identification is reverse causality from asset values to capital expenditures. The model implies that depreciation and obsolescence reduce the market value of the asset, hence the owner's incentive to invest in CAPEX. In order identify the effect of CAPEX on market values, we rely on two structural issues associated with CAPEX projects in real estate. First, these projects, such as renovations and expansions, take a significant time to plan. Second, once planned and initiated, they take a significant time to complete. These timescales are simply a result of the planning and construction process. The actual effect on the market value of the asset is thus revealed with a delay; it only becomes apparent once the CAPEX project is completed. We expect that CAPEX completed by the end of year $t-1$ affect market values in year $t$. Market values in year $t$ may well affect future CAPEX, but not past CAPEX. As a result, the structural idiosyncrasies of the planing and construction process in real estate CAPEX projects allows us to use a lag structure in order to identify the effect of CAPEX on market values.

In testing Hypothesis 4, a potential threat to identification is that CAPEX and the decision to hold or sell the property are simultaneously determined. The choice to invest in CAPEX implies the choice to hold on to the asset, but only until the CAPEX project is completed. Once a given CAPEX project is completed, the owner may well choose to dispose of the asset as shown in the model. Therefore, we are again able to use lag structures in order to identify the effect of CAPEX on the subsequent decision to sell. We expect that CAPEX projects 
completed by the end of year $t-1$ affect the decision to sell the property in year $t$, consistent with a value-add strategy whereby investors continue to hold an asset until they have made sufficient improvements to generate a gain on sale. ${ }^{8}$

\section{Data}

We test our hypotheses in a sample of US direct real estate investments. We collect the required data on property and financial characteristics from NCREIF. We begin our analysis in 2000, the first year for which NCREIF covers a significant number of properties and offers the full breadth of capital expenditure data required for our analysis; we end in 2014.

Our initial sample is the entire NCREIF universe. We then focus on operating properties that form part of $N C R E I F^{\prime} s$ NPI and where the values for CAPEX are non-negative. ${ }^{9}$ Figure 3 shows the evolution of the number of properties in the final sample.

[Figure 3 about here.]

In addition to property characteristics and financial information, NCREIF reports a range of different types of capital expenditures. We focus on capital improvements and property expansions as well as tenant incentives and lease commissions. It is important to note that we do not consider routine repairs and maintenance. ${ }^{10}$

We supplement the asset-level data from NCREIF with the following macro data. For

\footnotetext{
${ }^{8}$ We control for exogenous reasons to sell, such as target fund life, which might impose a certain timeline on any CAPEX projects carried out on an investment, by including investor/ fund-type indicators.

${ }^{9}$ Those represent accounting anomalies where excess reserves for CAPEX projects were booked and then reversed when the actual cost of the projects was revealed.

${ }^{10}$ Another possibility is that CAPEX are used to reposition the building to a different use. This strategy is beyond the scope of our analysis.
} 
growth expectations and their volatility, we add up a quarterly time series of yields on the 10-year US Treasury and the quarterly risk premium on a benchmark for BBB-rated corporate bonds over the Treasury rate, as proxy for the typical real estate risk premium. From this, we subtract the current quarterly capitalization rate by property type and MSA to obtain an implied growth expectation by property type and MSA per quarter. We use the non-overlapping series of year-end values as our measure for growth expectations. We calculate the standard deviation of quarterly growth expectations over four quarters. We use the resulting non-overlapping series of annual standard deviations as our measure for the volatility of growth expectations. Interest rate and CPI inflation data is obtained from the Federal Reserve Bank of St Louis's Economic Database (FRED).

Table 1 presents the descriptive statistics for the 34,378 property-year observations in our final sample, with details on variable definitions and sources. All continuous variables are winsorized at 1st and 99th percentile to mitigate undue influence of outliers.

The unconditional probability of sale in any given year is 2.7 percent. ${ }^{11}$ CAPEX on expansion an improvement average $\$ 0.92$ per square foot (12.2 percent of NOI). In contrast, tenant incentives and lease commissions average $\$ 1.27$ per square foot (16.9 percent of NOI). We also note that our data set contains observations where capital expenditures is zero. This is a useful feature of the data set because it rules out sample selection bias. Selection bias occurs when a sample is restricted to observations where a variable of interest, such as capital expenditures, takes a certain value or exceeds a certain threshold, which would be a concern

\footnotetext{
${ }^{11}$ It is possible for a property to be bought and subsequently sold quickly, potentially within the same year. There are no instances of "flipping" properties in our final sample. No asset transacts more often than once in a given year.
} 
for our study if we only recorded a capital expenditures observation when capital expenditures is non-zero (and positive). However, our capital expenditures variables frequently take the value of zero, meaning that the decision not to invest in capital expenditures is included in the NCREIF data, mitigating this potential selection bias.

Property-type and MSA-level income growth expectations were approximately zero over the sample period, likely due to the negative influence of the Great Recession. However, growth expectations range from approximately $-5 \%$ to $+5 \%$. The volatility of growth expectations averages 0.3 percent, again with a significant range from 0.1 percent to 1.2 percent.

Building-level occupancy averages 91.5 percent over the study period, reflecting the sample focus on properties at a stabilized level of operation. In terms of past investment performance, the average building in our sample achieves an annual income return of 6.3 percent, and an annual appreciation return of 1.2 percent, the latter likely again influenced by the decline in asset values during the Great Recession. The average LTV ratio in our sample is low at 29.4 percent, reflecting the nature of the institutional investors in our sample, many of whom do not use leverage. The average asset size (age at acquisition) in our sample is just under 200,000 square feet (just over 14 years).

As far as property market statistics are concerned, the average property type/MSA-level cap rate is 6.3 percent, with an average annual transaction volume of approximately $\$ 124$ million. CPI inflation averages 2.1 percent per year over the study period.

[Table 1 about here.] 
Table 2 presents average CAPEX values per square foot and scaled by NOI for the different property types in our sample. The highest level of CAPEX on expansion and improvement (per square foot) is spent in the Hotel sector $(\$ 4.33)$, followed by Office $(\$ 1.40)$, Apartment $(\$ 1.24)$, Retail $(\$ 1.13)$, and then Industrial $(\$ 0.35)$. When measured as a percentage of NOI, the ordering of the most CAPEX-intensive sectors is almost the same, only the Apartment sector ranks just above the Office sector on this measure. This analysis suggests that Hotels are the most CAPEX-intensive property sector as far as expansion and improvement CAPEX are concerned. In terms of tenant incentives and lease commissions (per square foot), the Office sector is the most CAPEX-intensive (\$3.24), followed by Retail $(\$ 1.22)$, Industrial (\$0.63), Apartment $(\$ 0.22)$, and Hotel $(\$ 0.01)$. The ranking is the same when considering CAPEX scaled by NOI. This analysis reflects the tendency for investors to custom-fit space for tenants and compete for tenants by offering incentives in the office sector.

[Table 2 about here.]

Figure 4 shows the evolution of CAPEX on expansion and improvement as well as tenant incentives and lease commissions over time. The Figure suggests that these two types of CAPEX exhibit some differences in their cyclical patterns.

In the early part of our sample, CAPEX on expansion and improvement increased at an increasing rate. This trend reflects that, as per our model, higher income growth expectations trigger larger amounts of CAPEX as investors seek to capture the uplift in rent from restoring a building to its undepreciated state. CAPEX on expansion and improvement projects declined during the crisis and bottomed out in 2009, before resuming its cyclical upswing. 
Tenant incentives and lease commissions also increased during the early part of our sample, but at a decreasing rate, reflecting the strength of the occupier market in this period, which eased the pressure on investors to incentivize tenants during lease negotiations. Again, tenant incentives and lease commissions declined briefly during the crisis before picking up again. Tenant incentives and lease commissions resumed their cyclical upswing at a faster rate than expansion and improvement CAPEX as lease negotiations precede upward revisions of expected income growth, which then triggers expansion and improvement CAPEX.

[Figure 4 about here.]

Table 3 presents pairwise correlation coefficients between the variables in our study. The transaction indicator is positively correlated with tenant incentive and lease commission CAPEX but not significantly correlated with improvement and expansion CAPEX. We explore these unconditional results further in our regression analysis. The correlation between CAPEX per square foot and CAPEX scaled by NOI is approximately 70 percent, hence we focus the remainder of our discussions on CAPEX per square foot. We find no excessive correlations between any of the other variables, alleviating concerns around multicollinearity.

[Table 3 about here.]

Table 4 presents an unconditional multivariate analysis that highlights combinations of property characteristics that are empirically associated with higher CAPEX on expansion and improvement (Panel (a)) as well as tenant incentives and lease commissions (Panel (b)). For this analysis, we sort all property-year observations into quintiles ranked by the amount 
of CAPEX spent, with quintile 1 containing the lowest CAPEX properties and quintile 5 containing the highest CAPEX properties. We tabulate the mean property characteristics in each quintile, and test the hypothesis that these means differ significantly across the top and bottom quintiles.

Our analysis suggests that properties with the highest expansion and improvement CAPEX are in asset market segments with higher growth expectations and a lower volatility of growth expectations, consistent with model predictions. As expected, higher CAPEX are associated with lower occupancy. In terms of past performance, CAPEX are higher for properties with lower income returns, consistent with the observation that CAPEX mitigate losses in income due to depreciation and obsolescence. Higher CAPEX are also associated with lower cap rates and larger transaction volumes, consistent with our earlier observation that expansion and improvement CAPEX are carried out pro-cyclically. Further, CAPEX are higher for larger and older properties with higher LTV ratios. This analysis reinforces our prior observation that the dynamics of tenant incentives and lease commissions are different. For instance, our analysis suggests that tenant incentives and lease commissions are associated with lower growth expectations, higher cap rates, and lower appreciation returns.

[Tables 4 and 5 about here.]

Table 5 presents the same analysis for combinations of property characteristics associated with a higher likelihood of sale (Panel (a)) and a shorter holding period (Panel (b)). Panel (a) suggests that properties are more likely to be sold after tenant incentives and lease commissions, consistent with the strategy of leasing up a property and then disposing of it, 
and when growth expectations are lower. Lower growth expectations for the current HBU owner increase the chances of the SBU valuation exceeding the HBU valuation, creating an incentive to trade. Our findings also suggest that dispositions are associated with higher appreciation returns, consistent with the disposition effect.

The analysis of the holding period in Panel (b) provides a complementary perspective on those buildings that were sold in our sample, by focusing on the time that passed between acquisition and sale. Logically, longer holding periods are found to be associated with a lower likelihood of sale. Longer holding periods are also found to be associated with lower expansion and improvement CAPEX, younger properties, higher income returns, lower market liquidity and LTV ratios as well as higher lower appreciation returns. However, this perspective is conditional on a building being sold, whereas our model generates a prediction about which properties to sell.

\section{Results}

\subsection{Capital expenditures as a function of growth expectations and volatility}

Table 6 presents the estimated coefficients for the OLS regression of capital expenditures as a function of growth expectations and volatility as per Equation (14). Capital expenditures are measured as annual CAPEX per sq. ft. of the asset. The Table reports results for the two groups of capital expenditures (improvement and expansion, and tenant incentives and lease commissions) separately. Note that the hypotheses derived from the model apply mainly to expansion and improvement CAPEX. Thus, we interpret the results on tenant incentives and lease commissions as contrasting evidence. 
[Table 6 about here.]

To restate our hypotheses, we anticipate that expected income growth is positively related to subsequent capital expenditures (hypothesis 1), and that higher volatility of income growth is inversely related to subsequent capital expenditures (hypothesis 2).

Our results support hypothesis 1 for expansion and improvement CAPEX. The estimates suggest that a one standard deviation increase in growth expectations is associated with a \$0.05 increase in CAPEX per square foot. Relative to the mean of expansion and improvement CAPEX of $\$ 0.92$, that equates to an increase of approximately 5 percent. Our results support the notion that investors carry out expansion and improvement CAPEX in strong occupier markets in order to benefit from the uplift in income associated with restoring the asset to its undepreciated state.

If physical depreciation and economic obsolescence increase, then the payoff to capital expenditures is also higher. Thus, both factors act to increase the likelihood of capital expenditures. However, higher income growth is likely to occur jointly with lower rates of physical depreciation and economic obsolescence. As a result, the observed increase in the income growth expectation may stem from higher income growth or lower depreciation and obsolescence. At any given point in time, these two factors could counteract each other in the overall effect on subsequent capital expenditures. Yet, our results suggest that the income effect outweighs the depreciation and obsolescence effects, possibly because the latter effects materialize through the availability of competing undepreciated supply, which arguably takes time to enter the market given the lengthy construction process. 
Consistent with hypothesis 2, we find that a one standard deviation increase in the volatility of growth expectations is associated with a decline in expansion and improvement CAPEX of $\$ 0.09$, or approximately 8 percent relative to the mean. Our results are consistent with standard option theory in that volatility increases the value of the option to carry out CAPEX, reducing the likelihood of exercising the option.

Further consistent with model predictions, this positive relation between increases in growth expectations and subsequent capital expenditures is based on the relative strength of two competing factors, income and obsolescence, in determining the return to CAPEX. If expected income increases, then the payoff to restoring the asset to an undepreciated state is higher because the income that may be captured after a completed investment is higher.

As far as tenant incentives and lease commissions are concerned, our results suggest again that these expenditures follow different patterns. Our estimates suggest that a one standard deviation in growth expectations is associated with a reduction in CAPEX of almost $\$ 0.11$, or almost 14 percent relative to the mean of tenant incentives and lease commissions of $\$ 1.27$. Our results imply that a stronger leasing market with higher growth expectations relieves pressure on owners to compete for tenants via tenant incentives and lease commissions.

We find that tenant incentives and lease commissions are inversely related to volatility of growth expectations. In economic terms, a one standard deviation increase in volatility reduces these expenditures by almost $\$ 0.06$, or just over 7 percent relative to the mean. Our results imply that the option of employing tenant incentives and lease commissions also becomes more valuable when uncertainty is higher, consistent with standard option theory. 
As for the control variables, consistent with expectations we find that CAPEX are typically associated with lower occupancy, as they are unlikely to occur in a fully occupied building. Our results further suggest that CAPEX are higher in older and larger properties with lower income returns and lower LTV ratios. These findings are generally consistent across expansion and improvement CAPEX as well as tenant incentives and lease commissions.

\subsection{Capital expenditures and capital value}

Table 7 presents the estimated coefficients for the OLS regression of equation (15), that is, the natural logarithm of market value as a function of CAPEX. CAPEX are measured over the year prior to the measurement of market value as actual value effects of CAPEX may enter valuations with a delay. The Table reports results for the full study period. We

also replicate our estimations across recession versus non-recession sub-periods as defined by NBER recession dates for comparison.

As per hypothesis 3, we expect increases in capital expenditures to be positively related to subsequent market value. A relevant question for investors is whether CAPEX are capitalized fully into market values, or what proportion of CAPEX is capitalized into market values.

[Table 7 about here.]

We find that a one percent increase in expansion and improvement CAPEX is associated with an increase in market value of almost 29 percent. For tenant incentives and lease commissions, the economic effect is similar at almost 26 percent. These economic effects are smaller in expansionary periods and larger during recessions. These differences may suggest 
that investors commit to only the most profitable CAPEX projects during recessions as compared to more benign economic conditions.

Overall, our findings suggest that CAPEX are partially capitalized into market values. Thus, while CAPEX may increase market value, they may not increase capital appreciation returns. Investors may use our estimates to form expectations about the expected return to CAPEX.

Our findings in this section and the previous section relate to the literature on the optionality of capital expenditures as follows. For example, Bond, Shilling, and Wurtzebach (2014) find that CAPEX increase with market lease rates and our work is consistent with their findings. In addition, Peng and Thibodeau (2011) and Ghosh and Petrova (2015) find that capital expenditures decrease in the level of economic uncertainty, which increases the value of the option to delay improvements. Our work extends these prior studies in two ways. First, we study income and volatility specific to asset market segments rather than general economic uncertainty. Second, we consider a full set of investor choices that includes the capital expenditure option and the disposition decision. As a result, we derive a different set of predictions, underscoring the value of recognizing a fuller set of investor choices. Further, these previous studies find mixed evidence for whether, and if so, to what extent, capital expenditures are capitalized into asset values. Our results are more consistent with Ghosh and Petrova (2015), who find that CAPEX are to some extent incorporated into values. Next, we turn to the relationships between CAPEX and subsequent sales decisions, evidence for which is absent from the existing literature to date. 


\subsection{Disposition decisions and evidence for the disposition effect}

Table 8 presents the coefficients from the estimation of equation (16) testing our hypothesis concerning disposition decisions as a function of capital expenditures. To reiterate hypothesis (4), we expect that the likelihood of sale declines in CAPEX. This step of our analysis also allows us to reexamine the evidence for the disposition effect.

[Table 8 about here.]

Column 1 of Table 8 shows a baseline specification where we model the likelihood of sale as a function of past appreciation returns. The disposition effect implies that properties with stronger past appreciation returns are more likely to be sold. The coefficient estimate of 0.614 on the appreciation return translates into an odds ratio of approximately 1.85. In economic terms, this implies that for a one standard deviation increase in appreciation returns, the odds of an asset being sold over the subsequent year increase by 11 percent. Our baseline finding suggests that there is evidence consistent with the disposition effect.

Column (2) shows the results for the full model, taking into account active management in the form of capital expenditures. Consistent with hypothesis (4), we find that expansion and improvement CAPEX reduce the likelihood of sale. We find that the coefficient estimate for expansion and improvement CAPEX is -0.050 , translating into an odds ratio of approximately 0.95. In economic terms, this implies that for a one standard deviation increase in CAPEX, the odds of an asset being sold over the subsequent year decline by 11 percent. This change in the likelihood of sale is as large in economic terms as the change induced by a one standard deviation increase in appreciation returns, but the effect is in the opposite direction. 
Further, we find that an increase in tenant incentives and lease commissions by one standard deviation increases the likelihood of sale over the subsequent year by approximately 19 percent. Our results highlight fundamental differences between expansion and improvement CAPEX and tenant incentives and lease commissions. Our findings imply that expansion and improvement CAPEX increase the HBU valuation vis a vis the SBU valuation, reducing incentives for trade. Our evidence on tenant incentives and lease commissions is more consistent with a strategy of leasing up a building and selling with a higher occupancy rate.

Genesove and Mayer (2001) are the first to document loss aversion in real estate. Using data on the Boston housing market, they find that homeowners subject to losses on the sale of their home set higher asking prices, attain higher selling prices, and are significantly less likely to sell than other owners. They conclude that, consistent with the disposition effect, homeowners are reluctant to realize losses. Bokhari and Geltner (2011) extend this evidence to commercial real estate investors, who may be more sophisticated and thus less sensitive to loss aversion. Using a data set of US commercial real estate transactions, they confirm that investors facing a loss set higher asking prices, achieve higher transaction prices and experience a longer time-on-market, implying a lower likelihood of sale. Finally, Crane and Hartzell (2010) explore the evidence for the disposition effect in corporate-level REIT investments. They find that REIT managers also tend to sell strongly performing properties while continuing to hold poorly performing investments.

Prior work rules out some alternative explanations for the observed patterns, particularly in relation to the likelihood of sale, such as optimal tax timing, mean reverting property 
returns, and asymmetric information (Crane and Hartzell, 2010). ${ }^{12}$ However, the literature stops short of considering the possibility of a typical value-add investment strategy that requires holding the asset through a phase of poor performance until capital expenditures improve its value enough to produce a gain on sale. Our findings suggest that the evidence on the disposition effect in real estate may depend on accounting for active management.

\subsection{Additional implications}

We now explore two additional perspectives on our main findings. First, we study the possibility that the effects of growth expectations and their volatility on CAPEX differ across property types. In other words, we now identify the property sectors that drive our main finding of a positive relationship between income growth expectations and subsequent CAPEX as well as an inverse relationship between the volatility of growth expectations and subsequent CAPEX by adding interaction terms to the regression model from Equation (14). Table 9 presents the results. Apartment properties are the omitted category.

\section{[Table 9 about here.]}

Our analysis suggests that the baseline level of expansion and improvement CAPEX is highest for hotel properties, and lowest for industrial, confirming the results of our unconditional analysis. Further, we find that expansion and improvement CAPEX for hotel properties are most sensitive to variation in growth expectations, significantly more so than those for apartments (omitted category). On the other hand, CAPEX for industrial and office

\footnotetext{
${ }^{12}$ Another stream of literature examines disposition patterns when considering different property types (Collett, Lizieri, and Ward, 2003), national, regional and local economic drivers (Fisher, Gatzlaff, Geltner, and Haurin, 2004), and the role of tax-efficient transactions such as 1031 exchanges (Ling and Petrova, 2015).
} 
properties are significantly less sensitive to variation in growth expectations than apartments. The sensitivity of CAPEX in retail properties is consistent with the effect for apartments. As for the effects of volatility, CAPEX for hotel properties are again the most sensitive, with industrial showing the opposite result. Overall, our results again highlight the high level of baseline CAPEX in hotel properties, and suggest that hotel CAPEX are also significantly more sensitive to the economic environment. This finding is intuitive when considering the exceptionally short lease terms in hotels as compared to all other sectors.

For tenant incentives and lease commissions, we find that our overall result of a negative relationship between these expenditures and variation in growth expectations is driven by the hotel, industrial, office, and retail sectors, with apartments showing an insignificant result. Our finding of an inverse relationship between tenant incentives and lease commissions and the volatility of growth expectations is mainly driven by the office sector, again highlighting the importance of these devices for managing adverse conditions in office leasing markets.

The relationships between growth expectations, their volatility, and subsequent CAPEX may also depend on the size of CAPEX projects. In order to explore this possibility, we estimate a quantile regression for Equation (14) which distinguishes between the median, $75^{\text {th }}$ percentile and $95^{\text {th }}$ percentile of the CAPEX distribution. ${ }^{13}$ Table 10 presents the results.

[Table 10 about here.]

We find that for expansion and improvement CAPEX, our findings are mainly driven

\footnotetext{
${ }^{13}$ Our models have very little explanatory power for small CAPEX projects below the median of the distribution.
} 
by median-sized CAPEX, with the strongest effects for the largest CAPEX projects $\left(95^{\text {th }}\right.$ percentile of the CAPEX distribution). Conversely, for the relationship between growth expectations and tenant incentives and lease commissions, our findings are mostly driven by median sized and slightly larger expenditures $\left(75^{\text {th }}\right.$ percentile). For the relationship between the volatility of growth expectations and tenant incentives and lease commissions, our findings are mostly driven by the very largest expenditures $\left(95^{\text {th }}\right.$ percentile). Overall, our findings suggest that the dynamics of capital expenditures differ not only by the type of expenditure but also by the scope of the CAPEX investment project.

\section{Conclusion}

The existing evidence on the disposition effect in real estate ignores the active management decisions that occur during the holding period, notably capital expenditures. We develop testable predictions about the relationships between economic asset-market fundamentals, subsequent investments in different types of CAPEX, the implications for asset value, and the consequences for disposition decisions.

Our estimates support predictions from real option theory that investors increase expansion and improvement CAPEX during periods of higher expected income growth and reduce CAPEX in periods of higher volatility. We show that, depending on the type of CAPEX, approximately 25 to 30 percent of the investment are capitalized into values. We present novel evidence on the relationships between different types of CAPEX and subsequent disposition decision, a connection that is hitherto absent from the existing literature. Our findings suggest that the evidence for the disposition effect in real estate may depend on accounting 
for active management in the form of capital expenditures and the underlying economic drivers suggests by real option theory. 


\section{References}

Agarwal, S., I. Ben-David, And V. YAO (2017): "Systematic mistakes in the mortgage market and lack of financial sophistication," Journal of Financial Economics, 123(1), 42-58.

Agarwal, S., and B. Mazumder (2013): "Cognitive Abilities and Household Financial Decision Making," American Economic Journal: Applied Economics, 5(1), 193-207.

Agarwal, S., R. J. Rosen, and V. Yao (2016): "Why Do Borrowers Make Mortgage Refinancing Mistakes?," Management Science, 62(12), 3494-3509.

Baker, M., R. Greenwood, And J. Wurgler (2003): "The maturity of debt issues and predictable variation in bond returns," Journal of Financial Economics, 70(2), 261-291.

Baker, M., J. C. Stein, And J. Wurgler (2003): "When Does the Market Matter? Stock Prices and the Investment of Equity-Dependent Firms," Quarterly Journal of Economics, 118(3), 969-1005.

BAKer, M., AND J. Wurgler (2002): "Market timing and capital structure," Journal of Finance, 57(1), 1-30.

Baker, M., And J. Wurgler (2004): "A Catering Theory of Dividends," Journal of Finance, 59(3), 1125-1165.

Ben-David, I., And J. R. GRaham (2013): "Managerial Miscalibration," Quarterly Journal of Economics, 128(4), 1547-1584.

Ben-David, I., And D. Hirshleifer (2012): "Are Investors Really Reluctant to Realize Their Losses? Trading Responses to Past Returns and the Disposition Effect," Review of Financial Studies, 25(8), 2485-2532.

Bertola, G. (1998): "Irreversible investment," Research in Economics, 52(1), 3-37.

Bokhari, S., And D. Geltner (2011): "Loss aversion and anchoring in commercial real estate pricing: Empirical evidence and price index implications," Real Estate Economics, 39(4), 635-670.

(2016): "Characteristics of Depreciation in Commercial and Multifamily Property: An Investment Perspective," Real Estate Economics, Forthcoming.

Bond, S., J. D. Shilling, And C. H. Wurtzebach (2014): "Commercial Real Estate Market Property Level Capital Expenditures: An Options Analysis," Discussion paper, RERI Working Paper.

Collett, D., C. Lizieri, and C. Ward (2003): "Timing and the Holding Periods of Institutional Real Estate," Real Estate Economics, 31(2), 205-222.

Coval, J. D., And T. Shumway (2005): "Do Behavioral Biases Affect Prices?," Journal of Finance, 60(1), 1-34. 
Crane, A. D., And J. C. Hartzell (2010): "Is there a disposition effect in corporate investment decisions? Evidence from real estate investment trusts," Working Paper.

DAI, M., H. LiU, AND J. Xu (2015): "A Rational Explanation of Disposition Effect: Portfolio Rebalancing with Transaction Costs," Working Paper, National University of Singapore.

DellaVigna, S. (2009): "Psychology and Economics: Evidence from the Field," Journal of Economic Literature, 47(2), 315-372.

Dhar, R., And N. Zhu (2006): "Up Close and Personal: Investor Sophistication and the Disposition Effect," Management Science, 52(5), 726-740.

Dixit, A. K., AND R. S. PindyCK (1994): Investment under uncertainty. Princeton University Press.

Dorn, D., And G. STrobl (2015): "Rational Disposition Effects: Theory and Evidence," Working paper, Frankfurt School of Finance \& Management.

Fisher, J., D. Gatzlaff, D. Geltner, and D. Haurin (2004): "An Analysis of the Determinants of Transaction Frequency of Institutional Commercial Real Estate Investment Property," Real Estate Economics, 32(2), 239-264.

Frazzini, A. (2006): "The Disposition Effect and Underreaction to News," Journal of Finance, 61(4), 2017-2046.

Gabaix, X. (2014): "A Sparsity-Based Model of Bounded Rationality," Quarterly Journal of Economics, 129(4), 1661-1710.

Genesove, D., And C. Mayer (2001): "Loss Aversion and Seller Behavior: Evidence from the Housing Market," Quarterly Journal of Economics, 116(4), 1233-1260.

Ghosh, C., And M. Petrova (2015): "The Impact of Capital Expenditures on Property Performance in Commercial Real Estate," Journal of Real Estate Finance and Economics, Forthcoming.

Graham, J., And C. HARVEY (2001): "The theory and practice of corporate finance: evidence from the field," Journal of Financial Economics, 60(2), 187-243.

Guiso, L., P. Sapienza, And L. Zingales (2013): "The Determinants of Attitudes toward Strategic Default on Mortgages," Journal of Finance, 68(4), 1473-1515.

Ivković, Z., J. Poterba, And S. Weisbenner (2005): "Tax-Motivated Trading by Individual Investors," American Economic Review, 95(5), 1605-1630.

Kahneman, D., And A. TVersky (1982): "The psychology of preferences," Scientific American, 246(1), 160-173.

Kahneman, D., and A. N. Tversky (1979): "Prospect Theory: An Analysis of Decision under Risk," Econometrica, 47(2), 263-291. 
Ling, D., And M. Petrova (2015): "The Economic Impact of Repealing or Limiting Section 1031 Like-Kind Exchanges in Real Estate," Working Paper.

Odean, T. (1998): "Are Investors Reluctant to Realize Their Losses?," Journal of Finance, $53(5), 1775-1798$.

Peng, L., and T. G. Thibodeau (2011): "Interest Rate and Investment under Uncertainty: Evidence from Commercial Real Estate Capital Expenditures," Discussion paper, RERI Working Paper.

PinDyCK, R. S. (1988): "Irreversible Investment, Capacity Choice, and the Value of the Firm," American Economic Review, 78(5), 969-985.

Polk, C., And P. SAPienza (2009): "The Stock Market and Corporate Investment: A Test of Catering Theory," Review of Financial Studies, 22(1), 187-217.

Seru, A., T. Shumway, and N. Stoffman (2010): "Learning by Trading," Review of Financial Studies, 23(2), 705-739.

Shefrin, H., and M. Statman (1985): "The Disposition to Sell Winners Too Early and Ride Losers Too Long: Theory and Evidence," Journal of Finance, 40(3), 777-790.

Shefrin, H. M., And R. H. Thaler (2004): "Mental Accounting, Saving, and Self-Control," in Advances in Behavioral Economics, ed. by C. Camerer, G. Loewenstein, and M. Rabin, Roundtable Series in Behavioral Economics, pp. 395-428. Princeton University Press.

Thaler, R. (1980): "Toward a positive theory of consumer choice," Journal of Economic Behavior \& Organization, 1(1), 39-60.

Thaler, R. H. (2004): "Mental Accounting Matters," in Advances in Behavioral Economics, ed. by C. Camerer, G. Loewenstein, and M. Rabin, Roundtable Series in Behavioral Economics, pp. 75-103. Princeton University Press.

(2008): "Mental accounting and consumer choice," Marketing Science, 27(1), 15-25, Conference of the Association-for-Consumer-Research, San Francisco. 


\section{$7 \quad$ Figures and Tables}

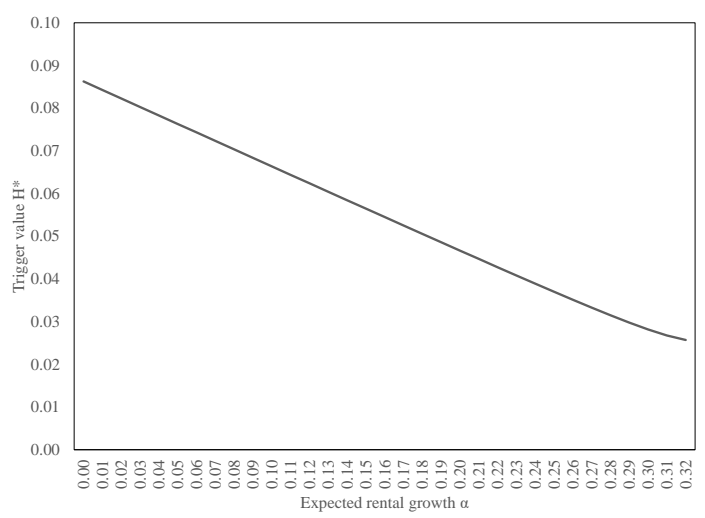

(a) $H^{*}$ as a function of expected income growth $\alpha$

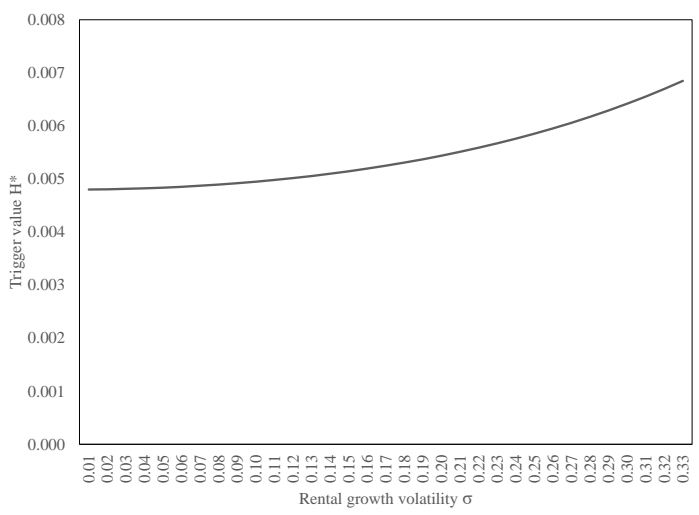

(b) $H^{*}$ as a function of income growth volatility $\sigma$

Figure 1: Evolution of threshold values $H^{*}$ as a function of income growth and volatility. The figure shows the evolution of the threshold levels of rent $H^{*}$ that trigger investment in capital expenditures as a function of expected rental growth $\alpha$ (Panel (a)) and volatility of rental growth $\sigma$ (Panel (b)). 


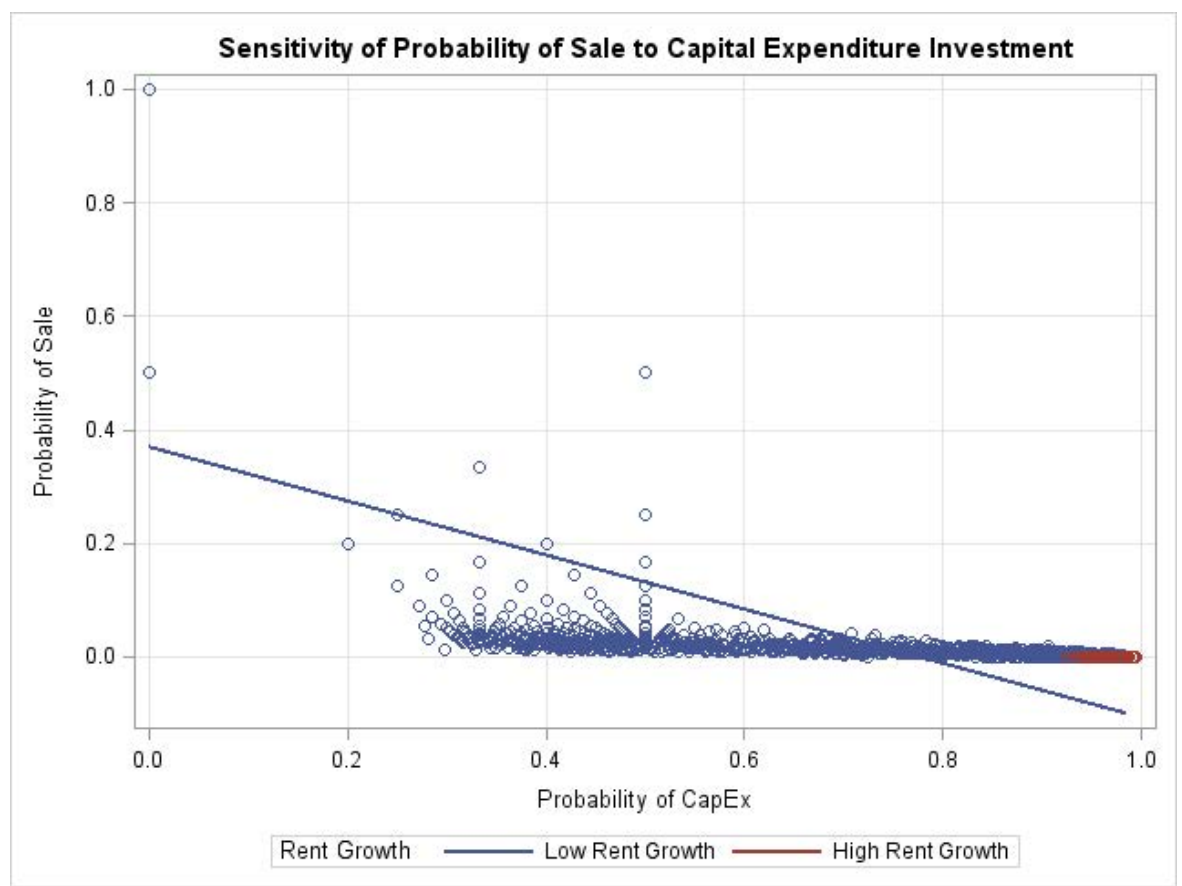

(a) Probability of sale as a function of CAPEX for different $\alpha$

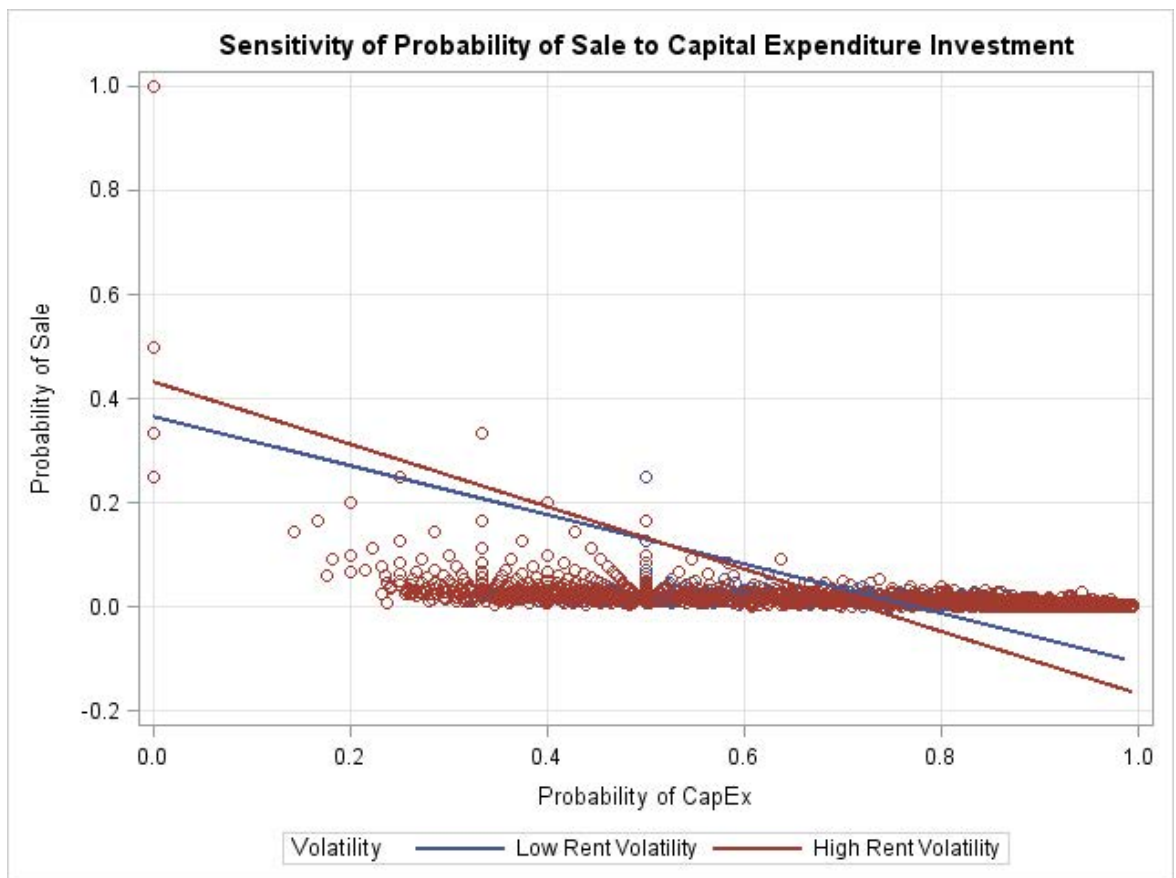

(b) Probability of sale as a function of CAPEX for different $\sigma$

Figure 2: Evolution of the probability of sale as a function of capital expenditures. The figure shows the probability of sale as a function of CAPEX with different levels of income growth $\alpha$ (Panel (a)) and volatility of income growth $\sigma$ (Panel (b)). 


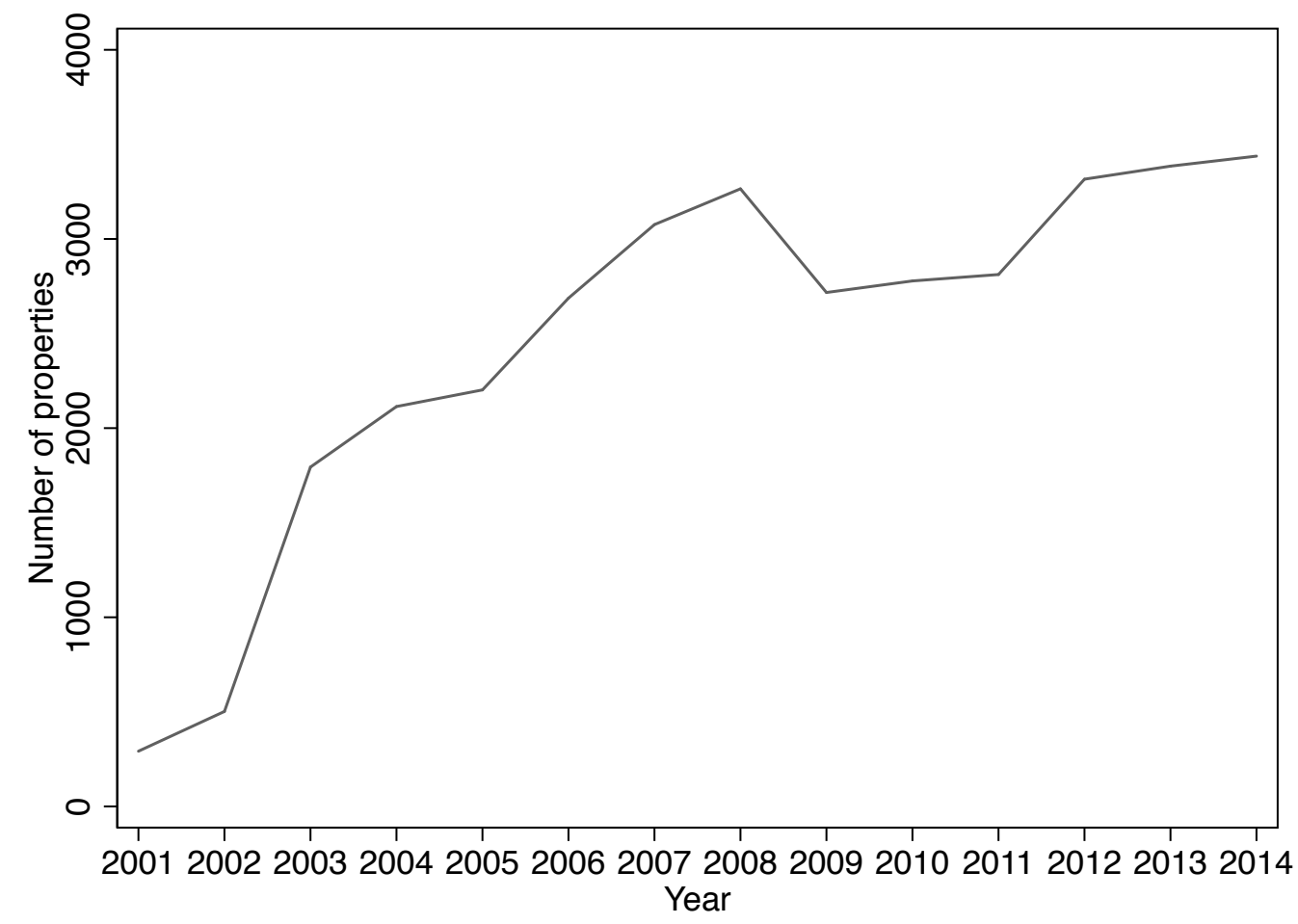

Figure 3: Evolution of sample properties. The figure shows the evolution of the quarterly number of properties in our final sample over the period 2001 to 2014. 


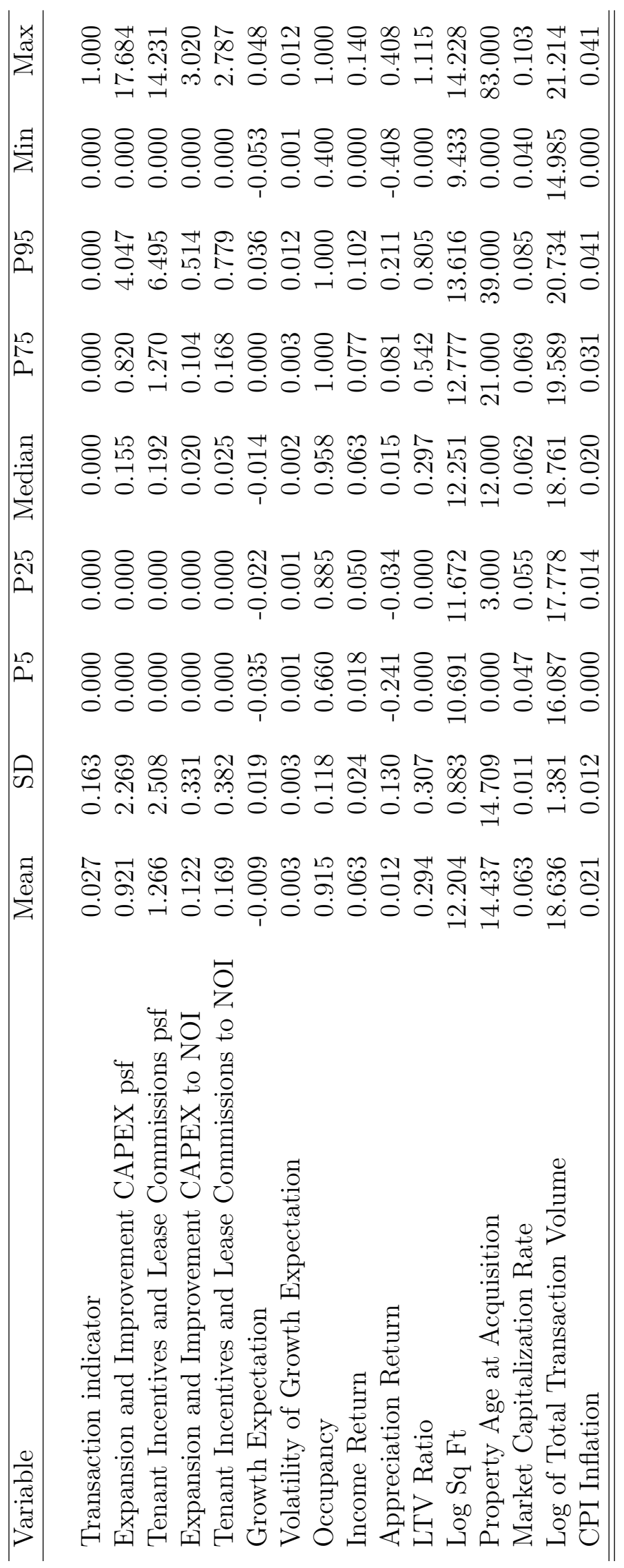

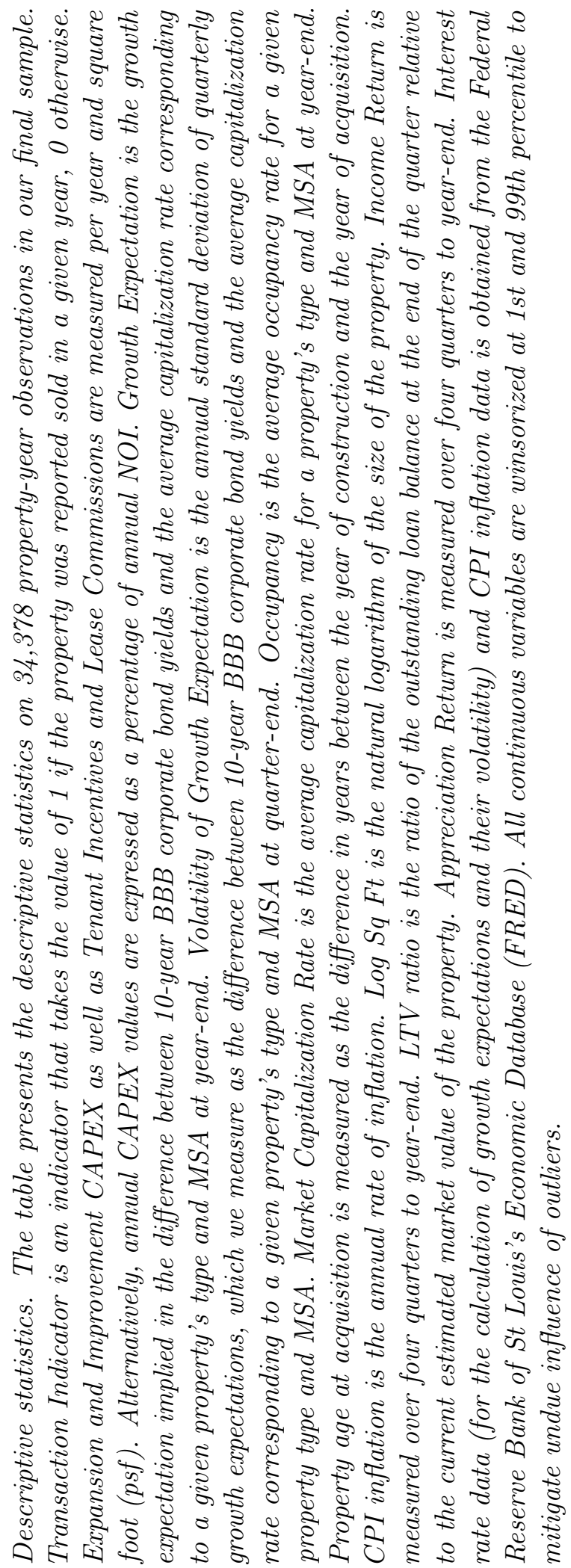
苛 


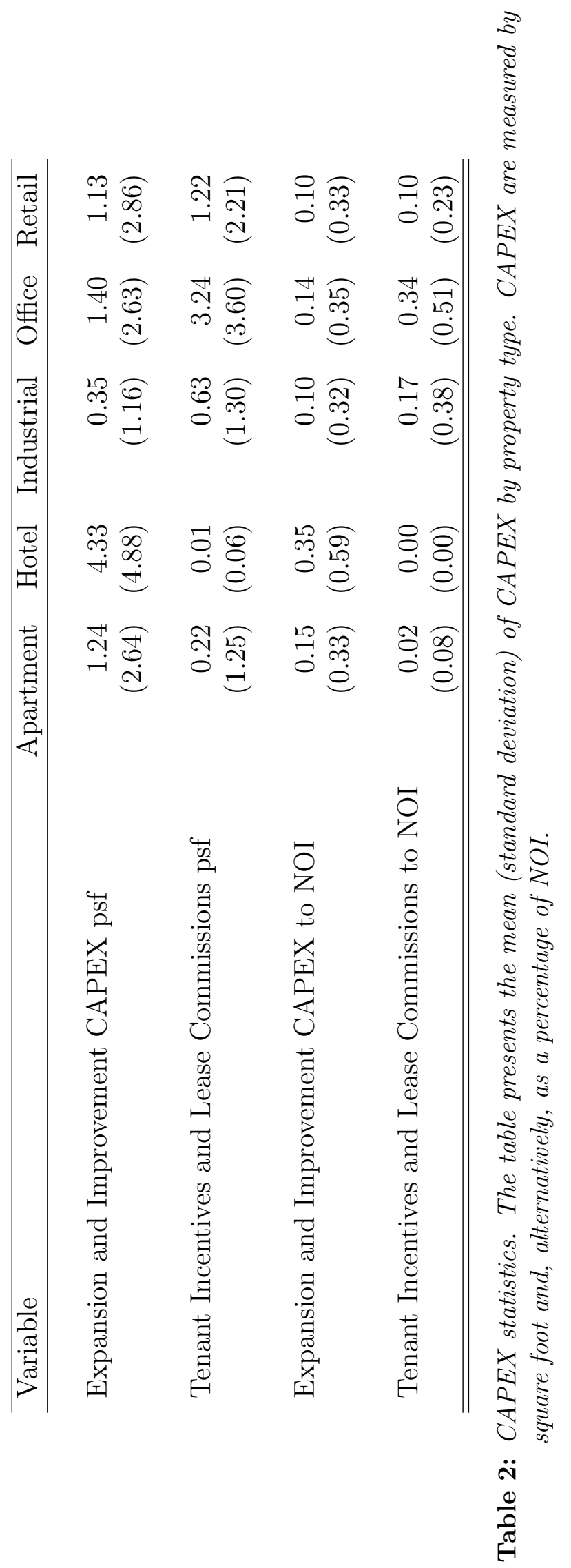




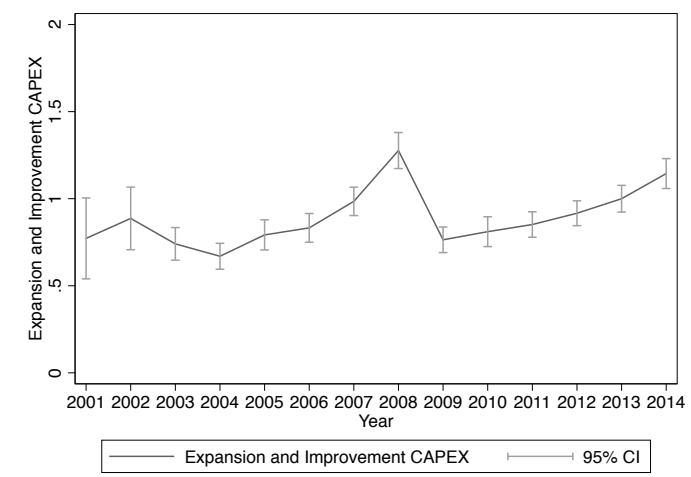

(a) Expansion and improvement CAPEX measured psf

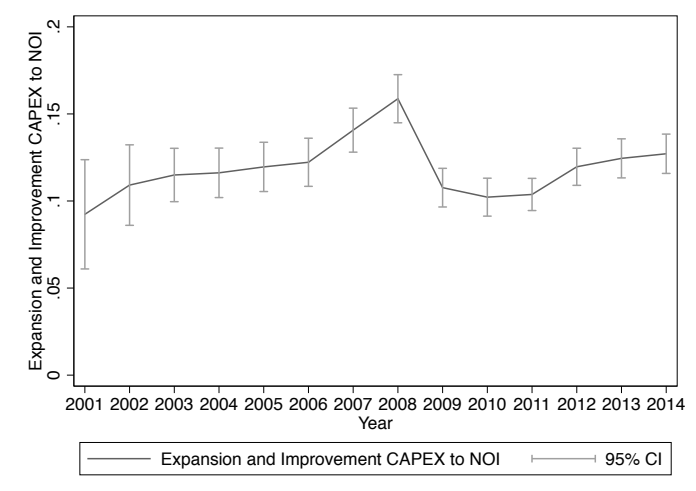

(c) Expansion and improvement CAPEX as a percentage of NOI

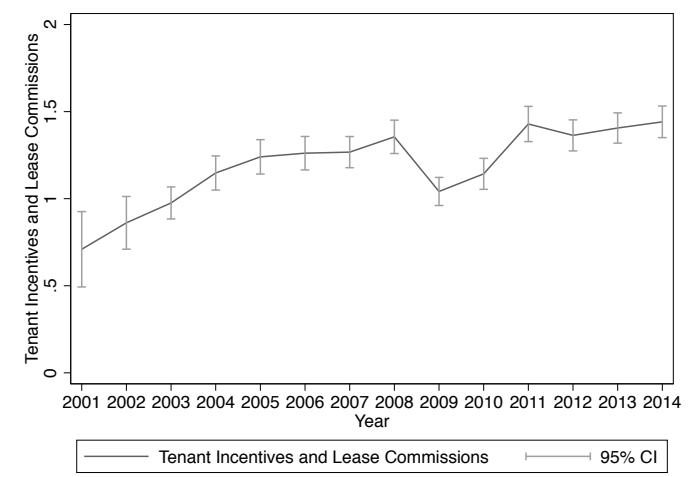

(b) Tenant incentives and lease commissions measured psf

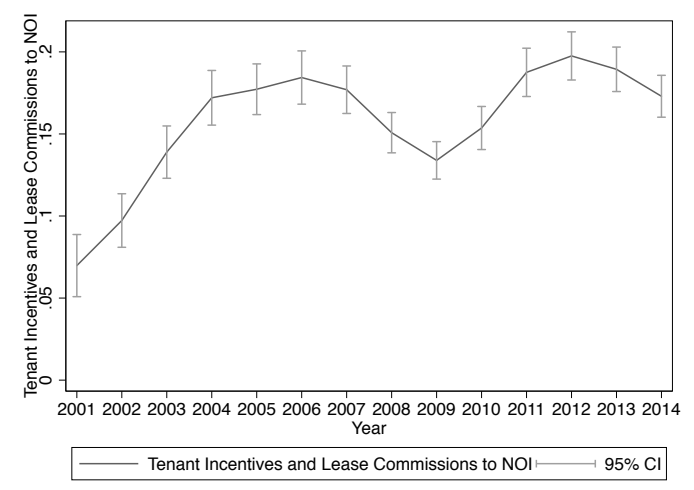

(d) Tenant incentives and lease commissions as a percentage of NOI

Figure 4: Evolution of CAPEX components. The figure shows the evolution of expansion and improvement CAPEX per square foot (Panel (a)) and scaled by NOI (Panel (b)). The figure also shows tenant incentive and lease commission CAPEX per square foot (Panel (c)) and scaled by NOI (Panel (d)) over the period 2001 to 2014. 


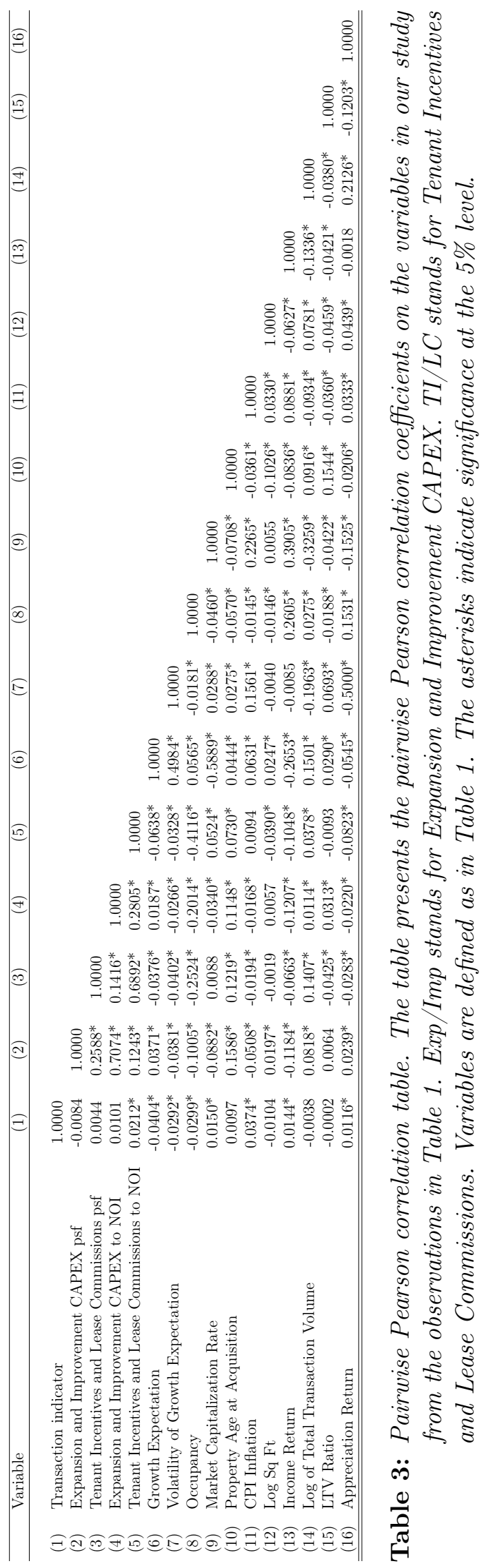




\begin{tabular}{|c|c|c|c|c|c|c|c|}
\hline Panel (a) & 1 & 2 & 3 & 4 & 5 & Difference & (t-statistic) \\
\hline Exp/Imp CAPEX & 0.000 & 0.023 & 0.170 & 0.668 & 3.765 & $3.765^{* * *}$ & $(104.09)$ \\
\hline Growth Expectation & -0.010 & -0.013 & -0.010 & -0.008 & -0.008 & $0.002 * * *$ & $(5.64)$ \\
\hline Volatility of Growth Expectation & 0.004 & 0.003 & 0.003 & 0.004 & 0.003 & $-0.000^{*}$ & $(-2.17)$ \\
\hline Occupancy & 0.940 & 0.911 & 0.910 & 0.905 & 0.889 & $-0.051^{* * *}$ & $(-28.83)$ \\
\hline Market Capitalization Rate & 0.064 & 0.064 & 0.063 & 0.062 & 0.062 & $-0.002^{* * *}$ & $(-13.08)$ \\
\hline Property Age at Acquisition & 12.046 & 12.989 & 13.563 & 14.934 & 19.317 & $7.271^{* * *}$ & $(32.52)$ \\
\hline CPI Inflation & 0.021 & 0.021 & 0.021 & 0.021 & 0.021 & -0.000 & $(-0.53)$ \\
\hline Log Sq Ft & 12.025 & 12.359 & 12.284 & 12.320 & 12.268 & $0.244^{* * *}$ & $(17.95)$ \\
\hline Income Return & 0.067 & 0.063 & 0.062 & 0.061 & 0.058 & $-0.008^{* * *}$ & $(-21.99)$ \\
\hline Log of Total Transaction Volume & 18.522 & 18.549 & 18.564 & 18.703 & 18.859 & $0.336^{* * *}$ & $(16.02)$ \\
\hline LTV Ratio & 0.273 & 0.291 & 0.310 & 0.314 & 0.293 & $0.020 * * *$ & $(4.29)$ \\
\hline Appreciation Return & 0.009 & 0.029 & 0.012 & 0.015 & 0.010 & 0.001 & $(0.26)$ \\
\hline Panel (b) & 1 & 2 & 3 & 4 & 5 & Difference & (t-statistic) \\
\hline $\mathrm{TI} / \mathrm{LC}$ & 0.000 & 0.018 & 0.212 & 0.987 & 5.138 & $5.138 * * *$ & $(172.72)$ \\
\hline Growth Expectation & -0.007 & -0.020 & -0.011 & -0.011 & -0.010 & $-0.004^{* * *}$ & $(-13.24)$ \\
\hline Volatility of Growth Expectation & 0.004 & 0.002 & 0.003 & 0.003 & 0.003 & -0.000 & $(-1.40)$ \\
\hline Occupancy & 0.948 & 0.943 & 0.925 & 0.898 & 0.854 & $-0.094^{* * *}$ & $(-58.64)$ \\
\hline Market Capitalization Rate & 0.061 & 0.062 & 0.064 & 0.065 & 0.064 & $0.003^{* * *}$ & $(20.08)$ \\
\hline Property Age at Acquisition & 11.781 & 12.941 & 14.614 & 15.985 & 18.016 & $6.235^{* * *}$ & $(28.05)$ \\
\hline CPI Inflation & 0.021 & 0.017 & 0.021 & 0.021 & 0.021 & -0.000 & $(-0.67)$ \\
\hline Log Sq Ft & 12.176 & 12.219 & 12.251 & 12.224 & 12.194 & 0.018 & $(1.36)$ \\
\hline Income Return & 0.062 & 0.066 & 0.065 & 0.065 & 0.060 & $-0.002^{* * *}$ & $(-4.39)$ \\
\hline Log of Total Transaction Volume & 18.63624 & 18.69631 & 18.42028 & 18.50798 & 18.96829 & $0.332^{* * *}$ & $(16.50)$ \\
\hline LTV Ratio & 0.292 & 0.302 & 0.321 & 0.294 & 0.269 & $-0.023^{* * *}$ & $(-5.05)$ \\
\hline Appreciation Return & 0.021 & 0.034 & 0.013 & 0.008 & -0.004 & $-0.025 * * *$ & $(-12.72)$ \\
\hline
\end{tabular}

Table 4: Unconditional multivariate analysis based on CAPEX. The table presents the characteristics of the properties in our sample over the period 2001-2014 when sorted into quintiles by quarterly CAPEX values. Panel (a) sorts by Expansion and Improvement CAPEX values. Panel (b) sorts by Tenant Incentives and Lease Commissions. All variables are defined as in Table 1. The Table also shows the spread (Difference) between the mean variable values across the 5th (highest) and 1st (lowest) CAPEX quintiles alongside the corresponding t-statistic from a two-group mean-comparison test. For the transaction indicator, the Table presents the differences between sold and unsold properties. Significance is indicated as follows: ${ }^{*} p<0.1,{ }^{* *} p<0.05$, *** $p<0.01$. 


\begin{tabular}{|c|c|c|c|c|c|c|c|}
\hline Panel (a) & 1 & 2 & & & & Difference & (t-statistic) \\
\hline Transaction Indicator & 0.000 & 1.000 & & & & 1.000 & $\mathrm{n} / \mathrm{a}$ \\
\hline Exp/Imp CAPEX & 0.924 & 0.808 & & & & -0.091 & $(-1.55)$ \\
\hline $\mathrm{TI} / \mathrm{LC}$ Commissions & 1.264 & 1.332 & & & & $0.149^{* *}$ & $(2.62)$ \\
\hline Growth Expectation & -0.009 & -0.014 & & & & $-0.006^{* * *}$ & $(-10.90)$ \\
\hline Volatility of Growth Expectation & 0.004 & 0.003 & & & & $-0.001^{* * *}$ & $(-7.62)$ \\
\hline Occupancy & 0.915 & 0.894 & & & & $-0.025^{* * *}$ & $(-7.99)$ \\
\hline Market Capitalization Rate & 0.063 & 0.064 & & & & $0.001^{*}$ & $(1.98)$ \\
\hline Property Age at Acquisition & 14.413 & 15.289 & & & & $0.926^{*}$ & $(2.28)$ \\
\hline CPI Inflation & 0.021 & 0.024 & & & & $0.002^{* * *}$ & $(5.34)$ \\
\hline Log Sq Ft & 12.206 & 12.150 & & & & $-0.092^{* * *}$ & $(-3.85)$ \\
\hline Income Return & 0.063 & 0.065 & & & & 0.001 & $(1.88)$ \\
\hline Log of Total Transaction Volume & 18.63646 & 18.60453 & & & & -0.0184 & $(-0.48)$ \\
\hline LTV Ratio & 0.294 & 0.293 & & & & -0.005 & $(-0.67)$ \\
\hline Appreciation Return & 0.012 & 0.021 & & & & $0.008^{*}$ & $(2.54)$ \\
\hline Panel (b) & 1 & 2 & 3 & 4 & 5 & Difference & (t-statistic) \\
\hline Holding Period & 2.907 & 5.428 & 6.258 & 8.093 & 14.231 & $11.323^{* * *}$ & $(52.43)$ \\
\hline Transaction Indicator & 0.581 & 0.519 & 0.530 & 0.509 & 0.458 & $-0.123^{* * *}$ & $(-3.40)$ \\
\hline Exp/Imp CAPEX & 1.212 & 0.714 & 0.711 & 0.575 & 0.766 & $-0.446^{*}$ & $(-2.48)$ \\
\hline $\mathrm{TI} / \mathrm{LC}$ & 1.311 & 1.443 & 1.602 & 1.391 & 1.497 & 0.185 & $(0.90)$ \\
\hline Growth Expectation & -0.014 & -0.014 & -0.014 & -0.014 & -0.014 & -0.000 & $(-0.18)$ \\
\hline Volatility of Growth Expectation & 0.003 & 0.003 & 0.004 & 0.003 & 0.003 & 0.000 & $(0.95)$ \\
\hline Occupancy & 0.886 & 0.890 & 0.894 & 0.885 & 0.898 & 0.013 & $(1.31)$ \\
\hline Market Capitalization Rate & 0.065 & 0.064 & 0.066 & 0.065 & 0.065 & 0.000 & $(0.28)$ \\
\hline Property Age at Acquisition & 18.217 & 16.414 & 15.685 & 13.732 & 10.571 & $-7.646^{* * *}$ & $(-6.79)$ \\
\hline CPI Inflation & 0.023 & 0.023 & 0.024 & 0.023 & 0.024 & 0.000 & $(0.03)$ \\
\hline Log Sq Ft & 12.272 & 11.925 & 12.053 & 12.166 & 12.336 & 0.064 & $(0.99)$ \\
\hline Income Return & 0.058 & 0.067 & 0.071 & 0.068 & 0.070 & $0.012^{* * *}$ & $(6.44)$ \\
\hline Log of Total Transaction Volume & 18.67206 & 18.44747 & 18.54283 & 18.45056 & 18.33297 & $-0.339 * * *$ & $(-3.50)$ \\
\hline LTV Ratio & 0.339 & 0.386 & 0.335 & 0.200 & 0.150 & $-0.190 * * *$ & $(-9.11)$ \\
\hline Appreciation Return & 0.027 & 0.011 & -0.015 & 0.018 & 0.003 & $-0.023^{* *}$ & $(-2.65)$ \\
\hline
\end{tabular}

Table 5: Unconditional multivariate analysis based on dispositions. The table presents the characteristics of the properties in our sample over the period 2001-2014 when sorted into quantiles based on dispositions. Panel (a) sorts by the value of the transaction indicator. Panel (b) sorts property-year observations into quintiles by time to sale (Holding Period) measured in years. All variables are defined as in Table 1. The Table also shows the spread (Difference) between the mean variable values across the 5th (highest) and 1st (lowest) CAPEX quintiles alongside the corresponding t-statistic from a two-group mean-comparison test. For the transaction indicator, the Table presents the differences between sold and unsold properties. Significance is indicated as follows: ${ }^{*} p<0.1,{ }^{* *} p<0.05,{ }^{* * *} p<0.01$. 


\begin{tabular}{lcccc}
\hline & \multicolumn{2}{c}{$\begin{array}{c}\text { Expansion \& } \\
\text { Improvement }\end{array}$} & $\begin{array}{c}\text { Tenant Incentives \& } \\
\text { Lease Commissions }\end{array}$ \\
Variable & Coefficient & t-statistic & Coefficient & t-statistic \\
\hline & $2.391^{*}$ & 1.91 & $-5.788^{* * *}$ & -5.21 \\
Growth Expectation & $-29.522^{* * *}$ & -4.52 & $-18.711^{* * *}$ & -3.12 \\
Volatility of Growth Expectation & $-6.810^{* * *}$ & -6.11 & 1.069 & 1.01 \\
CPI Inflation & $-1.310^{* * *}$ & -9.28 & $-3.717^{* * *}$ & -23.00 \\
Occupancy & $0.021^{* * *}$ & 12.04 & $0.010^{* * *}$ & 6.92 \\
Property Age at Acquisition & $0.045^{* *}$ & 2.09 & $0.073^{* * *}$ & 3.77 \\
Log Sq Ft & $-5.081^{* * *}$ & -7.42 & $-2.996^{* * *}$ & -4.22 \\
Income Return & 0.137 & 1.14 & -0.022 & -0.17 \\
Appreciation Return & -0.887 & -0.45 & $-16.384^{* * *}$ & -8.41 \\
Market Capitalization Rate & 0.007 & 0.60 & 0.018 & 1.60 \\
Log of Total Transaction Volume & $-0.187^{* * *}$ & -3.41 & $-0.131^{* *}$ & -2.45 \\
LTV Ratio & $1.985^{* * *}$ & 5.08 & $3.364^{* * *}$ & 8.72 \\
Constant & & & & \\
& 34,378 & & 34,378 & \\
Observations & 0.086 & & 0.268 & \\
R-squared & $\mathrm{Y}$ & & $\mathrm{Y}$ & $\mathrm{Y}$ \\
Property type FE & $\mathrm{Y}$ & & 9,401 & \\
Fund type FE & $\mathrm{Y}$ & & & $\mathrm{Y}$ \\
Division FE & 9,401 & & & \\
No of property clusters & & & & \\
\hline \hline
\end{tabular}

Table 6: Regression results for capital expenditures as a function of growth expectations and volatility. The table presents the coefficient estimates and corresponding t-statistics from the OLS estimation of equation (14). Variables are defined as in Table 1. All right-hand side variables are lagged by one year to mitigate simultaneity bias as a potential source of endogeneity. Fixed effects for property type, fund type, and geographic division are included as indicated. Standard errors are clustered by property. Significance is indicated as follows: ${ }^{* * *} p<0.001,{ }^{* *} p<0.01,{ }^{*} p<0.05$. 


\begin{tabular}{|c|c|c|c|c|c|c|}
\hline \multirow[b]{2}{*}{ Variable } & \multicolumn{2}{|c|}{ Full study period } & \multicolumn{2}{|c|}{ Non-Recession } & \multicolumn{2}{|c|}{ Recession } \\
\hline & Coefficient & t-statistic & Coefficient & t-statistic & Coefficient & t-statistic \\
\hline $\operatorname{Ln}(\operatorname{Exp} / \operatorname{Imp})$ & $0.285^{* * *}$ & 11.90 & $0.245^{* * *}$ & 10.26 & $0.427^{* * *}$ & 6.27 \\
\hline $\operatorname{Ln}(\mathrm{TI} / \mathrm{LC})$ & $0.257^{* * *}$ & 13.82 & $0.190^{* * *}$ & 11.59 & $0.510^{* * *}$ & 10.60 \\
\hline CPI Inflation & $-3.464^{* * *}$ & -8.81 & $-4.738^{* * *}$ & -8.68 & $18.006^{* * *}$ & 4.36 \\
\hline Occupancy & $1.274^{* * *}$ & 21.31 & $1.189^{* * *}$ & 18.99 & $1.698^{* * *}$ & 12.22 \\
\hline Property Age at Acquisition & $-0.004^{* * *}$ & -5.70 & $-0.003^{* * *}$ & -4.24 & $-0.009^{* * *}$ & -6.54 \\
\hline Log Sq Ft & $-0.050^{* * *}$ & -5.37 & $-0.053^{* * *}$ & -5.30 & -0.023 & -1.61 \\
\hline Income Return & $-3.549^{* * *}$ & -12.86 & $-3.679 * * *$ & -12.80 & $-2.878^{* * *}$ & -4.09 \\
\hline Appreciation Return & $0.515^{* * *}$ & 12.55 & $0.559 * * *$ & 12.73 & $0.462^{* * *}$ & 2.88 \\
\hline Market Capitalization Rate & $-8.058^{* * *}$ & -13.19 & $-8.027^{* * *}$ & -12.58 & $-14.597 * * *$ & -6.60 \\
\hline Log of Total Transaction Volume & $0.033^{* * *}$ & 6.88 & $0.038 * * *$ & 7.27 & 0.014 & 1.39 \\
\hline LTV Ratio & -0.011 & -0.48 & -0.006 & -0.24 & $-0.139^{* * *}$ & -2.81 \\
\hline Constant & $3.969^{* * *}$ & 24.28 & $4.021^{* * *}$ & 23.31 & $4.029 * * *$ & 11.94 \\
\hline Observations & 34,378 & & 30,821 & & 3,557 & \\
\hline R-squared & 0.337 & & 0.314 & & 0.601 & \\
\hline Property type FE & $\mathrm{Y}$ & & $\mathrm{Y}$ & & $\mathrm{Y}$ & \\
\hline Fund type FE & Y & & Y & & Y & \\
\hline Division FE & Y & & Y & & $\mathrm{Y}$ & \\
\hline No of property clusters & 9,401 & & 9,210 & & 3,498 & \\
\hline
\end{tabular}

Table 7: Regression results for property market value as a function of CAPEX variables. The table presents the coefficient estimates and corresponding t-statistics from the OLS estimation of equation (15). Exp/Imp stands for Expansion and Improvement CAPEX. TI/LC stands for Tenant Incentives and Lease Commissions. Variables are defined as in Table 1. All right-hand side variables are lagged by one year to mitigate simultaneity bias as a potential source of endogeneity. Fixed effects for property type, fund type and geographic division are included as indicated. Standard errors are clustered by property. Significance is indicated as follows: *** $p<0.001,{ }^{* *} p<0.01,{ }^{*} p<0.05$. 


\begin{tabular}{|c|c|c|c|c|}
\hline \multirow[b]{2}{*}{ VARIABLES } & \multicolumn{2}{|c|}{$(1)$} & \multicolumn{2}{|c|}{$(2)$} \\
\hline & Coefficient & t-statistic & Coefficient & t-statistic \\
\hline Appreciation Return & $0.614^{* *}$ & 2.32 & 0.241 & 0.72 \\
\hline Income Return & & & $5.373^{* * *}$ & 3.49 \\
\hline Expansion and Improvement CAPEX & & & $-0.050 * *$ & -2.52 \\
\hline Tenant Incentives and Lease Commissions & & & $0.073^{* * *}$ & 5.20 \\
\hline Growth Expectation & & & $-24.305^{* * *}$ & -7.58 \\
\hline Volatility of Growth Expectation & & & -7.450 & -0.38 \\
\hline CPI Inflation & & & $26.691^{* * *}$ & 9.04 \\
\hline Percent Leased & & & $-1.429 * * *$ & -5.14 \\
\hline Property Age at Acquisition & & & $0.007^{* * *}$ & 2.94 \\
\hline Log Sq Ft & & & $-0.123^{* * *}$ & -3.19 \\
\hline Market Capitalization Rate & & & $-17.785^{* * *}$ & -3.97 \\
\hline Log of Total Transaction Volume & & & -0.014 & -0.48 \\
\hline LTV Ratio & & & $-0.258^{* *}$ & -2.13 \\
\hline Constant & $-3.050^{* * *}$ & -20.72 & 0.156 & 0.20 \\
\hline Observations & 34,378 & & 34,378 & \\
\hline Property type FE & $\mathrm{Y}$ & & $\mathrm{Y}$ & \\
\hline Fund type FE & $\mathrm{Y}$ & & $\mathrm{Y}$ & \\
\hline Division FE & $\mathrm{Y}$ & & $\mathrm{Y}$ & \\
\hline No of property clusters & 9,401 & & 9,401 & \\
\hline
\end{tabular}

Table 8: Regression results for the sale indicator as a function of CAPEX variables. The table presents the coefficient estimates and corresponding t-statistics from the Logit estimation of equation (16). Column (1) shows the baseline specification with only past appreciation return and fixed effects as a proxy for the disposition effect. Column (2) includes the full set of predictors. Variables are defined as in Table 1. Exp/Imp stands for Expansion and Improvement CAPEX. TI/LC stands for Tenant Incentives and Lease Commissions. All right-hand side variables are lagged by one year to mitigate simultaneity bias as a potential source of endogeneity bias. Fixed effects for property type, fund type, and geographic division are included as indicated. Standard errors are clustered by property. Significance is indicated as follows: ${ }^{* * *} p<0.001,{ }^{* *} p<0.01,{ }^{*} p<0.05$. 


\begin{tabular}{|c|c|c|c|c|}
\hline \multirow[b]{2}{*}{ Variable } & \multicolumn{2}{|c|}{$\begin{array}{l}\text { Expansion \& } \\
\text { Improvement }\end{array}$} & \multicolumn{2}{|c|}{$\begin{array}{l}\text { Tenant Incentives \& } \\
\text { Lease Commissions }\end{array}$} \\
\hline & Coefficient & t-statistic & Coefficient & t-statistic \\
\hline Hotel & $5.267 * * *$ & 3.40 & & \\
\hline Industrial & $-1.102^{* * *}$ & -14.03 & $0.493^{* * *}$ & 9.31 \\
\hline Office & 0.033 & 0.32 & $3.147^{* * *}$ & 33.69 \\
\hline Retail & -0.110 & -0.78 & $1.098 * * *$ & 12.38 \\
\hline Growth Expectation & $10.120 * * *$ & 3.63 & -1.427 & -0.85 \\
\hline Hotel ${ }^{*}$ Growth Expectation & $52.831^{*}$ & 1.88 & & \\
\hline Industrial*Growth Expectation & $-13.463^{* * *}$ & -4.96 & $-4.994^{* * *}$ & -3.09 \\
\hline Office*Growth Expectation & $-7.673^{* *}$ & -2.43 & $-5.034^{* *}$ & -1.97 \\
\hline Retail*Growth Expectation & -6.228 & -1.49 & $-9.042^{* * *}$ & -3.65 \\
\hline Volatility of Growth Expectation & $-45.617 * * *$ & -3.08 & -0.747 & -0.08 \\
\hline Hotel*Volatility of Growth Expectation & $-370.100^{*}$ & -1.96 & & \\
\hline Industrial*Volatility of Growth Expectation & $48.421^{* * *}$ & 3.33 & 4.696 & 0.52 \\
\hline Office*Volatility of Growth Expectation & -2.712 & -0.16 & $-73.331^{* * *}$ & -4.75 \\
\hline Retail*Volatility of Growth Expectation & 8.343 & 0.38 & 0.119 & 0.01 \\
\hline CPI Inflation & $-7.008^{* * *}$ & -6.23 & 1.110 & 1.04 \\
\hline Occupancy & $-1.279^{* * *}$ & -9.07 & $-3.705^{* * *}$ & -22.82 \\
\hline Property Age at Acquisition & $0.021^{* * *}$ & 12.00 & $0.010^{* * *}$ & 6.77 \\
\hline Log Sq Ft & $0.046^{* *}$ & 2.10 & $0.076^{* * *}$ & 3.88 \\
\hline Income Return & $-5.176^{* * *}$ & -7.55 & $-3.067 * * *$ & -4.30 \\
\hline Appreciation Return & 0.193 & 1.62 & -0.033 & -0.26 \\
\hline Market Capitalization Rate & -0.724 & -0.36 & $-17.028^{* * *}$ & -8.65 \\
\hline Log of Total Transaction Volume & 0.015 & 1.31 & $0.021^{*}$ & 1.80 \\
\hline LTV Ratio & $-0.176^{* * *}$ & -3.22 & $-0.128^{* *}$ & -2.38 \\
\hline Constant & $1.862^{* * *}$ & 4.76 & $3.258^{* * *}$ & 8.42 \\
\hline Observations & 34,378 & & 34,302 & \\
\hline R-squared & 0.089 & & 0.27 & \\
\hline Fund type FE & 9401 & & 9350 & \\
\hline Division FE & & & & \\
\hline No of property clusters & 9,401 & & 9,350 & \\
\hline
\end{tabular}

Table 9: Regression results for capital expenditures with property type-specific effects. The table presents the coefficient estimates and corresponding t-statistics from the OLS estimation of equation (14). In the regression for tenant incentives and lease commissions, we omit Hotels, as Table 2 indicates that there are no meaningful capital expenditures of that type in the Hotel sector. Variables are defined as in Table 1. All right-hand side variables are lagged by one year to mitigate simultaneity bias as a potential source of endogeneity. Fixed effects for fund type and geographic division are included as indicated. Standard errors are clustered by property. Significance is indicated as follows: ${ }^{* * *} p<0.001,{ }^{* *} p<0.01$, * $p<0.05$. 


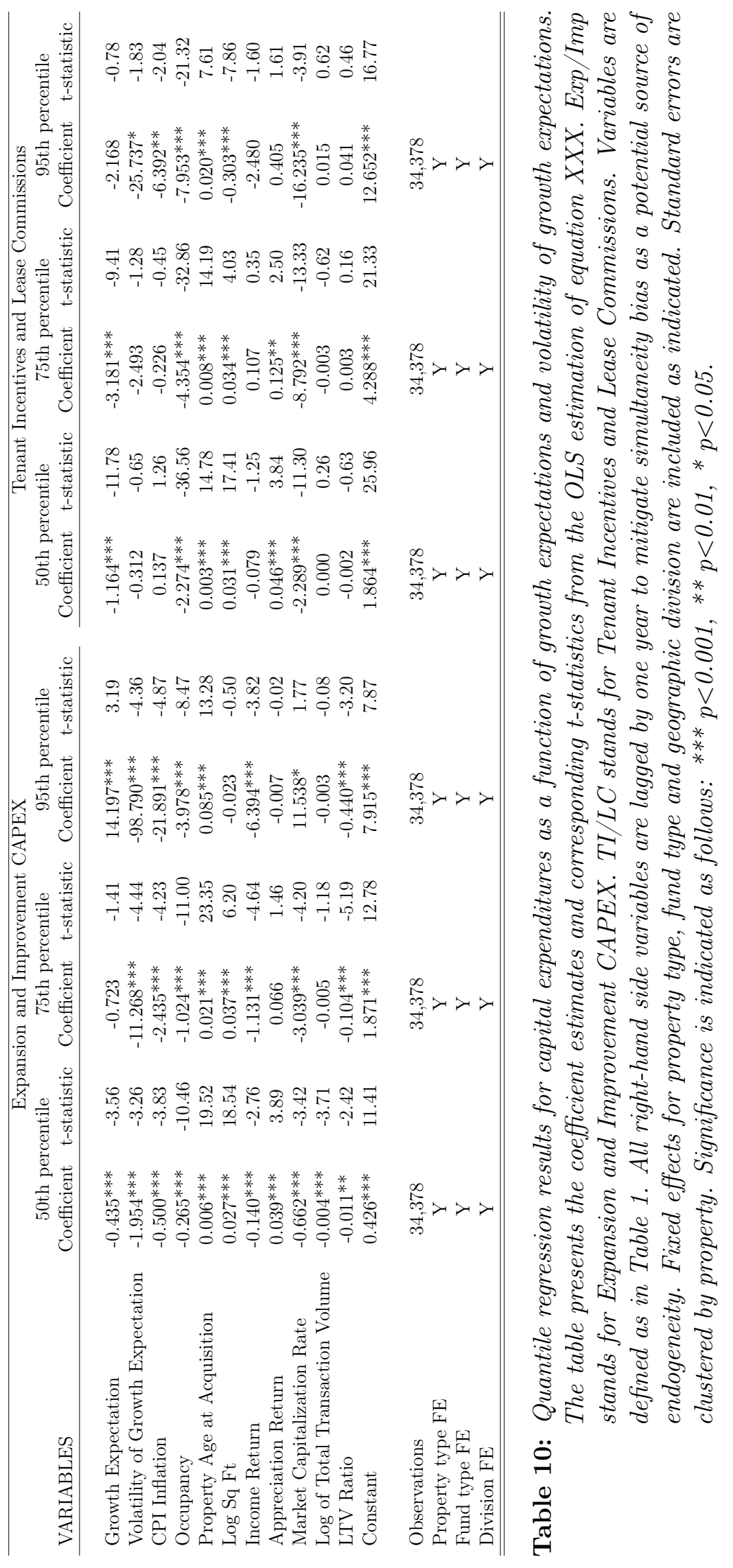

